\title{
Public service broadcasting in the digital world ${ }^{*}$
}

\author{
Mark Armstrong \\ University College London \\ Helen Weeds \\ University of Essex
}

26 July 2005

\section{Introduction}

The concept of public service broadcasting is for many people summed up by the mission given to the BBC by its first Director General, John Reith, in the 1920s: to 'inform, educate and entertain'. This broad statement encompasses several elements, some clearly appealing to viewers themselves (to entertain), others with wider social purposes (to educate and inform). ${ }^{1,2}$ The aims of public service broadcasting would therefore appear to encompass two main strands: that television should give people the programmes that they want to watch, and that it should also satisfy wider social purposes such as education and the promotion of 'citizenship'. Reflecting these strands, in this chapter we discuss two broad questions concerning the provision of television broadcasting: ${ }^{3}$

- Will the television broadcasting market give people what they want to watch?

- Should people be allowed to watch only what they want to watch?

The first question investigates the traditional 'market failure' arguments for public intervention in broadcasting. These hold that the commercial broadcasting market will fail to meet viewers' demands in a number of important respects. Advertisingfunded broadcasters will produce a bland diet of low quality programmes, appealing to mass market tastes and ignoring niche interests. We explore the basis for these arguments by assessing market provision of television broadcasting. Specifically, we

* The authors would like to thank Chris Giles, Robin Mason, Paul Seabright, Jon Stern, John Vickers and Mark Williams for helpful comments and discussion. The views expressed and any errors are those of the authors.

1 The UK government has suggested expanding the BBC's mission statement with five distinctive purposes: 'sustaining citizenship and civil society; promoting education and learning; stimulating creativity and cultural excellence; representing the UK, its Nations, regions and communities; and bringing the UK to the world and the world to the UK'. See DCMS (2005), page 5.

2 Similar social purposes are found in PSB systems of other countries. The PSB Charter for Ireland's Radio Telifis Éireann (RTÉ) includes among its guiding principles 'the democratic, social and cultural values of Irish society'. NZ On Air, the funding body for PSB in New Zealand, states as its mission, 'to reflect and foster the development of New Zealand culture and identity through broadcasting'.

3 This chapter discusses television rather than radio. Some of the arguments we present do not apply to the latter medium: since subscription is rarely used for radio, the practical choice is 
consider whether audience numbers will be efficient; whether the level of advertising is appropriate; and whether the right mix of programmes, in terms of diversity and quality of content, will be produced.

The second question relates to issues that go beyond the desires of the individual viewer. It encompasses two broad concerns. First, that (some) viewers do not necessarily choose what it is in their own best interests to watch. Secondly, television viewing may have effects on the wider population that are ignored by the individual viewer (this is sometimes described as the 'citizen' rationale for $\mathrm{PSB}^{4}$ ). The first concern might justify controls on the broadcasting of certain harmful content, especially to protect children, while the latter would provide a basis for intervention to promote socially beneficial programmes and to restrict those causing social detriment. We examine the possible foundations of these concerns and their relevance in the modern broadcasting environment.

It is particularly important to subject the basis for public intervention in television to rigorous economic analysis at the present time. The sector is changing enormously due to the adoption of digital technologies. Digital signals relax spectrum constraints, greatly increasing the number of channels that can be broadcast. Encryption technologies facilitate charging of viewers, rather than (just) advertisers, making commercial broadcasters directly responsive to viewer demands. In addition, devices such as the personal video recorder (PVR) give viewers greater control over what they watch. These developments have critical and wide-ranging impacts on television broadcasting.

In light of these developments, the rationale for public intervention needs to be reexamined. Regulation that was appropriate to the earlier, analogue era may become unnecessary, and even undesirable, ${ }^{5}$ in the digital world. Although everyone would presumably agree that the mission to 'inform, educate and entertain' is a highly laudable one, and in this sense supports public service broadcasting, ${ }^{6}$ it needs to be questioned whether public intervention is still required to fulfil these aims. As was well expressed by Gavyn Davies (who subsequently served as chairman of the BBC from 2001 to 2004): ${ }^{7}$

'some form of market failure must lie at the heart of any concept of public service broadcasting. Beyond simply using the catch-phrase that public service broadcasting must "inform, educate and entertain", we must add "inform, educate and entertain in a way which the private sector, left

between public and advertising funding, and the latter gives rise to a number of market failures (see Section 3).

4 See Ofcom (2004a), page 9.

5 In particular, the presence in the market of a large, publicly funded broadcaster creates distortions to competition, arguably reducing the market's effectiveness in meeting viewer demands.

6 See, for example, Ofcom (2004a), page 48.

7 See Davies (1999), page 10. 
unregulated, would not do". Otherwise, why not leave matters entirely to the private sector?'

We argue that digital broadcasting greatly mitigates traditional market failures and, in this context, the market will give people broadly what they want to watch. In this sense, the 'market failure' basis for public service broadcasting falls away. A coherent rationale remains for more limited intervention to control the broadcasting of harmful material, and to promote educational and other programmes generating social benefits.

The implementation of public service broadcasting also calls for re-examination in light of digital broadcasting. Funding sources for existing systems of provision come under serious pressure in the digital world, threatening their long-term viability. At the very least, these systems need to adapt to survive. Moreover, in this world of viewer sovereignty, with a vast and varied range of programmes to choose from, the ability of 'worthy' public service content to gain audience attention is greatly diminished. This challenge calls for more innovative techniques to be used in reaching viewers, if public service messages are to be conveyed. An alternative view is that, given declining benefits and major costs of intervention, the time has now arrived when wide-ranging intervention is no longer appropriate.

The chapter proceeds as follows. In Section 2 we describe the structure and characteristics of the broadcasting industry. Section 3 investigates the first question posed above: will the market give people what they want to watch? Section 4 explores the second question: should people be allowed to watch only what they want? Alternative systems of provision are described in Section 5. Drawing on this analysis, we then assess the rationale for, and provision of, public service broadcasting in the analogue era (Section 6) and in the digital world (Section 7). A case study of the UK's system of provision and challenges for its future is given in Section 8. Section 9 concludes with a set of messages for students, researchers and policymakers.

\section{The broadcasting industry}

The broadcasting industry consists of a number of vertical stages, by means of which television programming is created, packaged and transmitted to viewers, and revenue is generated. Broadcasters are typically vertically integrated, ${ }^{8}$ with some outsourcing of programme production.

The four main elements of the broadcasting supply chain can be described as follows:

- programme production, e.g. making a movie or drama, filming a sports event, and news reporting;

8 The UK is unusual in having separated terrestrial transmission from broadcasting. 
- channel packaging: scheduling programmes into channels, packages and payper-view offerings;

- transmission to the viewer via terrestrial, satellite, cable or other platforms;

- revenue generation through licence fee collection, subscription and/or the sale of advertising airtime.

We examine the features of each stage in turn.

\section{Programme production}

Programme production incurs costs that do not vary with the number of viewers: once a programme has been created, it can in principle be viewed by an unlimited number of viewers. Television content is highly differentiated, consisting of a wide range of programme types (or 'genres') such as news and current affairs, documentaries, coverage of sports and cultural events, movies, dramas, comedies, and so on. Production of higher quality programmes typically incurs greater expenditure (e.g. better special effects in movies, authentic period dramas, comprehensive news reporting), though production costs also vary considerably between genres. ${ }^{9}$

\section{Channel packaging}

Individual programmes are usually packaged into channels that are broadcast as a continuous television feed. A channel might focus on a single type of programming that appeals to a specific interest group, or it may contain a range of genres. Channels may themselves be combined into packages (or 'bouquets') that are supplied as a bundle. Alternatively, programmes may also be shown on a 'pay-per-view' basis rather as part of a channel.

In the future programme downloads from the Internet may become a popular viewing method. Video download departs from the traditional model of 'linear' broadcasting by giving the viewer, rather than broadcaster, control over the timing of reception. In this case the role of channel packaging, as such, becomes redundant since the viewer, rather than the provider, determines the selection and timing of viewed content. Instead, the organisation and presentation of content libraries becomes an important role for providers. ${ }^{10}$

\section{Transmission}

Programmes can be transmitted to the viewer using many technologies. Historically in the UK and many other countries, radio and television broadcasters used terrestrial

9 The cost per hour of BBC-originated programmes is highest (and by a large margin) for drama, followed by film, sport and entertainment. Relatively cheap programme genres are news and weather, followed by children's programmes (including education). From BBC Annual Report and Accounts 2004/2005, Broadcasting facts and figures, Table 18.

10 This phenomenon can already be seen for music, with the growth of websites such as iTunes and Napster. 
(airwave) transmission, ${ }^{11}$ but recent decades have seen the emergence of cable and satellite distribution platforms. Analogue broadcasting requires each channel to have a dedicated frequency band. In digital broadcasting signals are converted into a digital format and, by means of compression and multiplexing techniques, this allows many more channels to be transmitted in the same bandwidth. Broadband networks, based on fixed or mobile telephone connections or emerging wireless technologies, may be used to deliver services similar to broadcasting (e.g. video downloads). With the growth of broadband, the traditional nature of broadcasting as a one-way, one-tomany, passive activity is likely to become increasingly interactive and personalised.

Transmission systems have substantial set-up costs, to build the transmission network and enable viewers' reception capability. ${ }^{12}$ Once infrastructure is in place, costs do not increase significantly with the number of programmes delivered, consisting only of the power required to broadcast the signal. Moreover, once broadcast, a signal can be picked up by anyone with the necessary receiving equipment: there is no incremental cost of transmitting a programme to an additional viewer. The viewer makes an initial investment in receiving equipment, after which no additional cost is incurred in receiving further broadcasts. Effective transmission capacity varies with signal type. Analogue transmission is relatively inefficient in its use of spectrum, ${ }^{13}$ placing a tight constraint on the number of programmes that can be broadcast simultaneously, while digital signals are much more efficient.

\section{Revenue generation}

In principle, four methods of revenue generation may be used to fund broadcasting activities:

- direct government grant funded from taxation;

- a compulsory licence fee levied on all television viewers; ${ }^{14}$

- direct viewer charges on a subscription or pay-per-view basis ('pay-TV'); and

- the sale of airtime to advertisers.

Broadcasting services funded from a licence fee or the sale of advertising alone are often described as 'free-to-air'. Government grants draw on funds raised from a wide tax base, but the amount given will be subject to political acceptability and budgetary

11 Though for a period in the UK wire broadcasting was also used for radio; see Coase (1948).

12 Terrestrial transmission requires a network of transmission sites, with masts and antenna systems, and the viewer must install an aerial. Satellite transmission uses transponders to broadcast the signal, while viewers need a dish and set-top box to pick this up and convert it for viewing. Cable transmission requires a cable to be laid to each viewer's premises. In each case the viewer must also purchase a television set.

13 Spectrum is the relevant resource for terrestrial transmission. In satellite transmission transponder capacity may become constrained, while cable capacity is the relevant factor in cable transmission. We refer to spectrum scarcity throughout, although it should be borne in mind that other resources may be the limiting factor for alternative transmission methods.

14 In the UK this is a flat-rate charge per household levied for possession of television-receiving equipment, and is set at $£ 126.50$ per annum in 2005-06 (for a colour TV). 
priorities. Throughout this chapter we mostly ignore government grants as a source of funding for broadcasting.

A licence fee appears straightforward but, in the absence of an effective exclusion mechanism, incurs significant enforcement costs. ${ }^{15}$ Pay-TV requires the installation of a conditional access system to exclude non-payers: the signal is broadcast in an encrypted format, and authorised viewers use a set-top box (STB) containing a decoder (or 'smart card') to convert it for viewing. ${ }^{16}$ Subscriber acquisition and management services, including a sophisticated billing system for levying charges that vary according to the channels taken, must also be set up.

Television advertising is a two-sided market in which the broadcaster shows attractive programming to draw in viewers, and access to this audience is sold to advertisers and sponsors. Although viewers may receive the programmes for free, they must tolerate, and be responsive to, advertisements placed between and within programmes. Disutility from the presence of adverts can be regarded as the implicit 'price' to viewers of advertising funded broadcasting. Viewers can adopt a number of measures to reduce this disutility: switching channel during advertising breaks - the invention of the remote control was a major step in this direction-or skipping adverts during playback from a VCR. The ability to eliminate adverts is further heightened by the invention of the personal video recorder (PVR, sometimes known by the brand name 'TiVo'). This is a new type of recording device offering high quality recording, much larger capacity and greater sophistication than the VCR. ${ }^{17}$ Such avoidance behaviour, however, reduces the impact of adverts and, if widespread, ultimately undermines the sale of advertising airtime as a source of funding for broadcasters. ${ }^{18}$

\section{Will the market give people what they want to watch?}

In this section we address the question, 'will market provision give people the programmes they want to watch?' There are several aspects to this. First, taking the set of programmes as given, will the efficient level of viewing be achieved? Revenue is needed to cover broadcasters' production and transmission costs, and so must be generated somehow, while viewing is sensitive to the method used. In Section 3.1 we assess the efficiency of market outcomes, considering in turn the television licence

15 In the UK the BBC's collection costs amounted to $£ 152 \mathrm{~m}$ in $2004-05$; additional court costs are not quantified. Its success is mixed, with evasion estimated at 5.0\% at March 2005, resulting in a total cost to the BBC of $10.2 \%$ of revenue. From BBC Annual Report and Accounts 2004/2005, Financial review.

16 As well as facilitating charging, encryption can prevent the inadvertent viewing of unwanted channels and (perhaps with the addition of a PIN mechanism) provides parents with a reliable mechanism to prevent children having access to unsuitable material.

17 Programmes are recorded onto a hard disk rather than a tape, allowing the viewer to record many more programmes and to move between them easily as with a CD or DVD. The PVR also has flexible viewing capabilities, allowing the viewer to pause and then resume viewing from the same point even while the programme is being broadcast.

18 See Wilbur (2004) for an analysis of PVR use on advertising revenue and broadcasting. 
fee, advertising funding and pay-TV. A strand of this analysis concerns advertising: advertisers, as well as viewers, are consumers of television services, and the two sides of the market are interdependent although not always aligned in their interests. Viewer and social welfare are affected by the level of advertising as well as programme viewing, thus both aspects must be assessed.

Turning next to production, we examine whether this is likely to be efficient. For production of a programme to be efficient the surplus it generates must exceed its cost. In Section 3.2 we note the role played by market prices in this context. A further aspect is whether the market will deliver the 'right' set of programmes, in terms of diversity and quality, that viewers want to watch. In Section 3.3 we examine programme selection under alternative funding systems to assess the diversity of genres produced in each case. Quality provision and investment in innovation are assessed in Section 3.4.

Throughout this section market outcomes are assessed against viewers' own demands, ignoring any effects of television viewing beyond the individual viewer. Thus, 'social optimality' refers here to outcomes that maximise viewers' own utility in the absence of externalities. In addition, the viewer is taken to be capable of determining what is in his or her own interests and making this selection for themselves; thus the possible concern that (some) viewers do not choose what is in their best interests to watch is ignored. These two issues are deferred until Section 4.

\subsection{Charging and consumption}

As described above, the broadcasting industry is characterised by substantial fixed costs while marginal, per-viewer costs are negligible. Programme production costs are independent of the number of viewers and, once transmission and reception capacity are in place, the marginal cost of transmitting the programme to an additional viewer is zero. Television viewing is a non-rivalrous form of consumption: viewing by one individual leaves unaffected the ability of others to view the same output. These characteristics are fundamental to the economics of broadcasting, with important implications for efficient production and consumption.

\section{Efficient viewing of programmes}

Once produced, allocative efficiency dictates that a programme should be viewed by all individuals whose consumption generates positive surplus. Since an existing programme can be supplied to an additional viewer at no incremental cost, this requires the programme to be provided to all viewers with a positive valuation of it, however small. Such an outcome can be achieved by setting the price of viewing equal to marginal cost-i.e. at zero. At this price all individuals with a positive valuation view the programme and consumption is at the efficient level. A source of revenue is needed, however, since production and transmission costs must somehow be covered for the industry to be viable. Appeals to allocative efficiency are often 
used to support funding in the form of a licence fee, or out of the public purse (though taxation elsewhere typically also creates distortions).

However, the zero price argument applies only to an existing set of programmes. It ignores the effect of such a policy on the incentive to develop desirable programmes in the future. A production function with high fixed and very low marginal costs is found in many other creative and innovative industries-books, software and pharmaceuticals, for example-yet these products are not supplied at marginal cost. Marginal cost pricing (even with a subsidy to cover fixed costs) gives poor incentives for high quality provision, innovation and cost efficiency. Balancing these arguments, some means of revenue generation must be found that minimises allocative inefficiency while also allowing costs to be covered and providing good incentives to producers.

\section{Efficient level of advertising}

The issue of allocative efficiency also arises on the advertising side of the market. However, the interests of advertisers and viewers are somewhat opposed. Advertisers benefit from the viewing of their advertisements, while viewers typically suffer some disutility from the disruption and delay imposed on the viewing of their desired programme.

The extent to which advertiser surplus enters into the social welfare function is important here. The welfare effect of advertising is a contentious issue. Advertising may be designed to provide information, change preferences or steal business from rivals, and the welfare assessment varies according to its purpose. In the case of informative advertising without business stealing, the advertiser's surplus should count fully in social welfare. Then, if an advertiser is willing to pay an amount $w$ per viewer to reach an audience while each viewer incurs a disutility $d$ from the presence of the advert, the advert should be provided whenever $w$ exceeds $d$. If this condition is violated allocative inefficiency arises on the advertising side of the market. If advertising is socially wasteful, on the other hand, welfare depends on viewer surplus plus broadcaster profits.

We now assess the efficiency of alternative methods of revenue generation, taking account of both viewing and advertising levels.

\section{Television licence fee}

Once the licence fee has been paid any programme may be viewed at no further charge. ${ }^{19}$ The fact that viewing is free at the point of consumption is often taken to

19 The same is also true for subscription channels, though not for pay-per-view. The difference between the licence fee and subscription is the size of the bundle of channels - with the licence fee covering all television (even if its revenues are given to a single broadcaster) - and the compulsory nature of the licence fee. 
entail that allocative efficiency is always achieved. However, allocative inefficiency may nonetheless arise in a number of ways.

The licence fee excludes consumption of all television services by individuals whose willingness to pay for television as a whole is less than this amount (and who do not simply evade the fee). Although this could in principle be a source of allocative inefficiency, almost universal coverage implies that such exclusion is not significant in practice (and some of those who choose not to have a television set may actively dislike television, thus their failure to watch is not inefficient).

More significant inefficiency can arise if a commercial broadcaster (say, pay- $\mathrm{TV}^{20}$ ) operates alongside the licence fee funded (public) broadcaster. The uptake and revenues of pay-TV are likely to be distorted, to the detriment of social welfare. Note that this would also be the case if the public broadcaster's channels were provided for free (e.g. if it is funded from taxation): even the availability of public television affects viewer choices, to the detriment of commercial operators. ${ }^{21}$

An individual who wants to watch any television - even pay-TV alone - must pay the licence fee. This alters her choice set by removing the option of taking only pay-TV. If choices were unconstrained, the pay-TV operator would gain a subscription from any viewer whose valuation of its offering, taken either on its own or in addition to the public channels, exceeds its subscription charge. But with a compulsory licence fee the viewer's choice is restricted to either paying the licence fee and watching only public channels, or paying a subscription charge in addition to the licence fee and having both services. With this constrained choice, the viewer subscribes to pay-TV only if her net surplus from the second option exceeds that of the first.

Some simple representations of preferences and choices are given in Box 1. The first example suggests that subscription to pay-TV may be inefficiently low in the presence of the compulsory licence fee. In the second example, subscription is unaffected but the licence fee diverts part of the viewer's surplus to the public broadcaster. In fact, the actual situation may be more complicated than this, since the subscription charge is likely to be lower when the pay-TV operator faces the compulsory licence fee. ${ }^{22}$ If so, pay-TV revenue (as well as viewer surplus) is diverted to the public broadcaster. ${ }^{23}$

20 A similar analysis can be applied to an advertising funded broadcaster, where the 'price' of its service is the time spent watching adverts on its channels.

21 As an analogy, consider the case of free newspapers on trains. Knowing that this is freely available, a traveller is less likely to buy another newspaper even if this is actually preferred.

22 The level of the licence fee may also be different in the two scenarios. Terrington and Dollar (2005) argue that if the licence fee were voluntary, it would have to be increased to offset the fall in uptake. This is a pessimistic counter-factual, however, since the public broadcaster would have an incentive to price its services efficiently, implying that not all viewers pay more, and might operate more efficiently if it had to compete for subscribers, reducing the costs it needed to cover.

23 If the commercial broadcaster were instead advertising funded, a similar analysis would imply that viewing time devoted to its channels, and hence the broadcaster's revenue, is inefficiently low. 
With lower revenue and tougher competition for viewers, it is likely that the output and quality of programming offered by pay-TV will be lower. ${ }^{24}$

\section{Box 1: Pay-TV and the licence fee}

\section{Case (i): Exclusion of pay-TV}

Consider a situation in which a single pay-TV operator (for simplicity) offers a single bundle of channels. Suppose that a viewer's ranking of net surplus (gross surplus minus the relevant charges) is given by:

$$
S(\text { pay })-P>S(\text { public })-L>S(\text { public }+ \text { pay })-L-P>0
$$

where $S($.$) denotes gross surplus from viewing public and/or pay-TV, P$ is the subscription charge for pay-TV and $L$ is the licence fee. This viewer prefers pay-TV to the public broadcaster's service, and has diminishing marginal utility of additional channels such that it is even less desirable for him to take both services given the charges involved.

The viewer's unconstrained choice would be to take pay-TV alone. But with the compulsory licence fee this choice is unavailable. Since his incremental valuation of pay-TV is negative-i.e. his net surplus from taking both services is less than that of having the public broadcaster's channels alone-he will not subscribe to pay-TV.

\section{Case (ii): Diversion of surplus}

Suppose that a viewer has a strong preference for pay-TV and a negative net surplus from public broadcasting, such that:

$$
S(\text { pay })-P>S(\text { public }+ \text { pay })-L-P>0>S(\text { public })-L \text {. }
$$

Again, the unconstrained choice would be pay-TV alone; but the constrained choice is to take pay-TV in addition to public broadcasting. The viewer pays the licence fee simply in order to take pay-TV, even though her valuation of the public broadcaster's output implies that this would not be chosen under a voluntary system. Part of the viewer's surplus is diverted to the public broadcaster, even though her net valuation of its channels is negative.

\section{Advertising funding}

Advertising funding avoids the need to levy subscription or licence fees on viewers to cover broadcasting costs. In the direct, monetary sense the price of a programme equals its marginal cost and allocative efficiency would appear to be achieved. However, advertising imposes on viewers a kind of 'hedonic' price given by their disutility from seeing adverts. Viewers must tolerate advertisements placed between and within programmes, imposing on them the disutility of disruption and delay. Given that the programmes have already been made and could be viewed without interruption, this is inefficient from the viewers' perspective. When transmission capacity is limited, advertising takes up valuable airtime that could otherwise be used to show more desirable programming. ${ }^{25}$

24 This may explain why the pay-TV sector has so far failed (in the view of some) to provide more diverse, high-quality programmes.

25 Advertising may be enjoyable to some viewers; if so, this should be taken into account in calculating the net cost of advertising. 
To the extent that broadcasters have market power over providing access to their audience, advertising rates may be set above the efficient level; but this is not necessarily so. Anderson and Coate (2005) analyse whether too much or too little advertising is supplied in equilibrium, for both free-to-air and pay-TV. ${ }^{26}$ In the case of free-to-air, the welfare outcome is ambiguous: advertising may be either overprovided (if its nuisance cost is high) or under-provided (if this cost is low). ${ }^{27}$ As the market for viewers becomes competitive, advertising may be under-provided since broadcasters compete for viewers by lowering advertising levels.

If viewers can avoid advertisements, e.g. by switching channel or using recording devices to skip over them, the scope for inefficiency is greater. A viewer will avoid adverts as long as the average cost incurred in doing so is less than $d$, the disutility of watching adverts. Even if the value to advertisers of viewer attention exceeds $d$, and advertisers would therefore be willing to compensate viewers for their disutility, no effective mechanism exists to pay viewers to watch. If widespread, avoidance behaviour could undermine advertising as a funding source for commercial television. The only viable advertising strategies would then be ones that are intertwined with the programme itself, e.g. programme sponsorship, product placement and advertisements captured by the programme (e.g. logos on Formula 1 cars, billboards in football stadiums).

\section{Pay-TV}

With conditional access, viewers may be charged directly for their consumption. However, even if feasible, direct viewer charges at the level necessary to recoup broadcasting costs may exclude a number of individuals whose consumption would be efficient. In particular uniform average cost pricing, levied on a per-programme or per-channel basis, could be expected to exclude many viewers.

Price discrimination is the key to combining fixed cost recovery through viewer charging with relatively efficient consumption. By charging different amounts to heterogeneous viewers, reflecting individual willingness to pay, surplus can be extracted from high valuation viewers to cover fixed costs while achieving (close to) the efficient level of consumption. ${ }^{28}$ Perfect (or first degree) price discrimination achieves allocative efficiency, but its implementation requires the supplier to know each viewer's willingness to pay, to be able to set charges individually, and to prevent resale. These conditions are rarely met in practice and instead mechanisms must be

26 This model involves informative advertising, and assumes that each viewer watches a single channel over the relevant time horizon.

27 If advertising is over-provided by commercial broadcasters this could be restricted by imposing a ceiling on the amount of airtime that may be devoted to advertising (as occurs in the EU under the Television Without Frontiers directive) or by providing advertising-free channels (such as those of a publicly funded broadcaster).

28 Coase (1946) advocates multi-part tariffs - a form of price discrimination - as a solution to the marginal cost controversy. 
found by which to identify groups of viewers with different valuations (third degree price discrimination) or to induce them to self-select between different charging schemes (second degree price discrimination).

Price discrimination in broadcasting is typically achieved by two means: 'windowing' and channel bundling. Windowing, whereby a movie or other content is released through a sequence of distribution outlets at successively lower prices, is a form of intertemporal price discrimination. Viewers with a strong preference for seeing a movie immediately, who tend to value the programme more highly than other individuals, pay a high price to see it at the cinema, while less time-sensitive viewers view it later at a lower price through video release or on television. Pay-per-view, pay-TV and free-to-air broadcasting each form a separate stage in this process. Windowing allows surplus to be extracted while most viewers with positive valuations view the programme eventually. Nevertheless, a real form of allocative inefficiency remains: there is no additional cost to providing the programme to everyone immediately, yet delay is imposed on many viewers.

The packaging of individual programmes into a channel supplied as a single offering is a form of product bundling, as is the combining of several channels into a bouquet. Pure bundling occurs when two or more products are supplied only as a bundle. ${ }^{29}$ Mixed bundling allows the components also to be sold separately, but the price of the bundle gives a discount on the sum of component prices. 'Tiering' - a form of mixed bundling in which channel are supplied as a hierarchy of packages between which subscribers select-is commonly used by pay-TV operators.

When two or more channels are supplied and viewer valuations are heterogeneous, channel bundling can be used as a price discrimination device to improve allocative efficiency. ${ }^{30}$ A simple, two channel example of pricing and consumption with no bundling, pure bundling and mixed bundling is given in Box 2; this demonstrates how bundling may improve allocative efficiency, as well as facilitating channel provision. The key mechanism underlying bundling is that the dispersion in valuations across viewers is lower for the bundle than for an individual channel. This is especially true if component values are negatively correlated, as in Box 2, but holds even for independent and positively correlated distributions. The benefits of bundling increase as the number of channels rises, due to the homogenising effect of the 'Law of Large Numbers'. When the number of channels is large, pure bundling may achieve (almost) universal consumption while also covering the costs of channel provision. ${ }^{31}$

29 In a sense, the TV licence fee could be regarded as the price of a pure bundle covering all television viewing.

30 For literature on the use of price discrimination to reduce allocative inefficiency see Adams and Yellen (1976), McAfee, McMillan and Whinston (1989), Armstrong (1999) and Bakos and Brynjolfsson (1999).

31 Such as for the licence fee when there are no other broadcasters; see earlier in this section. 
Mixed bundling increases the number of instruments available to the broadcaster and hence increases its revenue compared with pure bundling. ${ }^{32}$ The welfare comparison between pure and mixed bundling is ambiguous. A danger inherent in pure bundling schemes is that individuals may inefficiently consume some components that they value at less than cost. ${ }^{33}$ With the marginal cost of supply equal to zero, however, this inefficiency does not arise in broadcasting. One the other hand, mixed bundling may induce viewers to select smaller bundles (perhaps even a single channel) while forgoing channels for which they have a small but positive valuation; if so, allocative efficiency will be lower than under pure bundling. ${ }^{34}$ For this reason schemes that are closer to pure bundling, consisting of large packages and with few channels made available individually, are a particularly efficient form of pricing in the broadcasting industry. ${ }^{35}$

\section{Box 2: Channel bundling}

Suppose that two television channels, 1 and 2, can be supplied by a monopoly broadcaster to three viewers, A, B and C. The per-channel cost of production and transmission is $£ 10$, but once this is incurred the marginal cost of supplying an additional viewer is zero. Viewer valuations of the channels are shown in the table below; if an individual receives both channels the combined valuation is simply the sum of component valuations. For each channel the sum of viewer valuations exceeds its cost, thus provision of both channels is socially desirable. With all viewers having positive valuations of viewing each channel, allocative efficiency is achieved through universal consumption.

\begin{tabular}{l|cc}
\hline & Channel 1 & Channel 2 \\
\hline Viewer A & $£ 10$ & $£ 1$ \\
Viewer B & $£ 1$ & $£ 9$ \\
Viewer C & $£ 7$ & $£ 7$ \\
\hline
\end{tabular}

Denoting the prices of the individual channels as $P_{1}$ and $P_{2}$ respectively and the price of the bundle as $P_{B}$, profit-maximising prices can be calculated for three cases: no bundling, pure bundling and mixed bundling. Together with the sales of each channel $\left(Q_{1}, Q_{2}\right)$, revenue raised and consumer surplus (CS) generated, these prices are as follows:

- no bundling: $\quad P_{1}=P_{2}=£ 7 ; Q_{1}=Q_{2}=2 ;$ revenue $=£ 28 ; C S=£ 5$

- pure bundling: $P_{B}=£ 10 ; Q_{1}=Q_{2}=3$; revenue $=£ 30 ; C S=£ 5$

- mixed bundling: $P_{1}=£ 10, P_{2}=£ 9, P_{B}=£ 14 ; Q_{1}=Q_{2}=2 ;$ revenue $=£ 33 ; C S=0$.

32 At worst, the pure bundling outcome can be replicated in a mixed bundling scheme by setting very high component prices.

33 Adams and Yellen (1976) raise this possibility, noting that the 'exclusion' of such inefficient consumption is a desirable property of a mixed bundling scheme.

34 If channel production costs are very high, however, mixed bundling may be necessary to generate sufficient revenue to ensure provision.

35 Although this tends to be disliked by viewers who feel that they are forced to pay for programmes that they do not watch. Although understandable, this perception is based on the incorrect assumption that the sum of individual component prices (were these to be offered) would equal the price of the bundle, while economic principles tell us that bundles offer a discount on the sum of stand-alone prices. 
Pure bundling achieves allocative efficiency: each channel is consumed by all three viewers. Mixed bundling and no bundling, however, do not (in this case) achieve allocative efficiency.

Bundling raises broadcaster revenues, with mixed bundling extracting the most consumer surplus (here, all of it) and yielding the highest revenue. With a larger channel cost bundling may be necessary to ensure provision. If the per-channel cost is raised to $£ 15$, the firm cannot break even without some form of bundling. With a cost of $£ 16$ per channel, mixed bundling is then necessary.

In Box 2 it is assumed that the channel provider is a monopolist. In a monopoly context, bundling increases profits compared with pure component pricing. In competitive situations, however, this result may no longer hold. In a duopoly model of compatibility and bundling of complementary goods, Matutes and Regibeau (1992) show that bundling can act to reduce profits since it intensifies price competition. Strategic use of bundling is possible: for example, in the face of competitive entry bundling can be an exclusionary device. ${ }^{36}$ In a competitive broadcasting market the analysis of channel bundling is far from straightforward. ${ }^{37}$

When pay-TV broadcasters sell advertising airtime as well as levying charges to viewers, fewer adverts are shown compared to a pure advertising regime. ${ }^{38}$ Thus, advertisers are worse off under pay-TV, though viewers may benefit. In a model of informative advertising, Anderson and Coate (2005) show that advertising is underprovided by pay-TV. The reason being that, in their model, viewers watch a single channel, giving channels a monopoly over providing access to their viewers. The model in Appendix 1 shows that advertising avoidance behaviour (e.g. skipping adverts using a PVR) in a pay-TV regime typically makes viewers worse off, as they pay a higher subscription charge that outweighs the benefit to them of avoiding adverts.

\subsection{Programme production and asymmetric information}

In the preceding discussion the set of programmes was taken as given, considering only the need to cover programme costs which were treated as fixed. We now go back a stage and ask whether production will be efficient. We start by noting the role of the price mechanism in revealing hidden information about viewer preferences. We then turn to the questions of diversity, quality and innovation.

In general terms, a good should not be produced unless total surplus generated exceeds its production costs. Each viewer's valuation is known to the individual themselves but unknown to the producer; in other words, viewer valuations are asymmetric information. In a typical market the price mechanism reveals much of this hidden information: by purchasing the good at a given price, consumers reveal

36 See Whinston (1990). For a survey of the literature on bundling, see Nalebuff (2003).

37 In 2002 the UK Office of Fair Trading investigated BSkyB's mixed bundling its of premium channels (among other concerns); for the conclusions of this investigation see BSkyB: The outcome of the OFT's Competition Act investigation, Office of Fair Trading, December 2002.

38 This result is found in the model in Appendix 1. 
that their valuations are at least this amount. Since production is not profitable unless revenues exceed costs, inefficient over-production is avoided, although efficient production may not always take place (unless price discrimination is close to perfect).

In pay-TV, viewer charges reveal information about viewers' preferences, assisting efficient production decisions. ${ }^{39}$ In free-to-air broadcasting, however, this guide to viewer preferences is lacking. ${ }^{40}$ Viewer surveys might be conducted instead. ${ }^{41}$ However, such results are inferior to market data: questionnaires pose artificial choices, while market transactions are real ones, and statements about programme desirability are costless to make. Viewing patterns may reveal some information about relative valuations: analysis of choices between head-to-head combinations can yield some programme rankings. Even so, without an indication of willingness to pay the broadcaster cannot determine whether surplus generated by a programme exceeds its cost of provision and hence whether its production is efficient.

\subsection{Diversity of programmes}

Television content is a highly differentiated product class, including sports coverage, news and current affairs, movies, comedies, documentaries and so on. Viewer tastes are heterogeneous, with preferences differing across individuals and each viewer typically enjoying many genres. Provision of a diverse range of programme genres, other things being equal, tends to raise viewer surplus. Diversity in broadcasting is also important for the political process, with expression of a plurality of opinions being vital to the functioning of democratic systems. ${ }^{42}$

Market provision of diversity depends on the means of revenue generation, as this may give broadcasters an incentive either to focus on a limited number of tastes or to differentiate themselves across a range of genres. Outcomes under pay-TV and

39 Pay-per-view gives a direct measure of viewers' willingness to pay for individual programmes. Bundling, both of programmes into channels and of channels into packages, may obscure the valuations of particular programmes. However, in pay-TV a channel typically focuses on a single genre, implying that valuations of programmes within that channel do not differ greatly from that of the channel as a whole. Moreover, experimentation with channel and package contents allows the values of various programme genres to be estimated.

40 Coase (1946) notes this problem in the absence of a pricing system.

41 This is relevant to the $\mathrm{BBC}$, which levies no viewer charges (leaving aside the licence fee). DCMS (2005) proposes that the BBC Trust should measure audience opinion by means of quantitative and qualitative research, viewer consultation though e.g. elected regional Broadcasting Councils, open meetings, e-forums and research among 'representative groups' of viewers and listeners.

42 With a limited number of channels plurality of opinions can be sustained only if several viewpoints are put forward within each channel. This is reflected in the PSB obligation in the UK and elsewhere to provide comprehensive and balanced coverage of news and current affairs. No requirement of this nature is imposed on printed media, where the multiplicity of newspapers can represent a variety of views (although the tendency of people to read a single newspaper implies that a given individual will not necessarily receive diverse opinions). 
advertising funding have been studied at length by economists. We summarise these findings next. ${ }^{43}$

\section{Advertising funding}

With pure advertising funding the broadcaster's aim is to maximise audience size, as this increases advertising revenues, while the amount of surplus accruing to viewers is unimportant. ${ }^{44}$ Steiner (1952) assesses provision of diversity by competing singlechannel broadcasters in a market with a set of distinct programme types, each with a distinct set of viewers. Welfare is maximised by having just one channel per genre, up to the point where the number of channels equals the number of genres. If two or more channels target the same genre then its audience is divided equally between them. Steiner finds that duplication tends to arise: a broadcaster will duplicate an existing programme type, taking part of the audience from a competing channel, rather than produce one that is as yet unserved whenever its share of the audience for the former exceeds the total audience for the latter.

A simple example of channel diversity for a varying number of competing channels, based on Steiner's approach, is presented in Box 3. With limited channel numbers less popular genres tend to be left unserved while popular ones are duplicated. The precise extent of duplication depends on the distribution of viewer preferences, with a greater disparity in audience size raising the extent of duplication. As the number of channels increases, genres with successively smaller audiences are served. This analysis suggests that with a small, fixed number of channels, competition performs worse than multi-channel monopoly since business-stealing between broadcasters results in duplication.

The Steiner model is special in a number of ways and its conclusions regarding the impact of competition do not necessarily carry over to more general models. Beebe (1977) allows viewers to have a second choice programme that is preferred to not watching at all, and shows that competition might produce more desirable outcomes than suggested by Steiner. Anderson and Coate (2005) explicitly model viewers' disutility of advertising and allow free-to-air broadcasters to decrease the amount of advertising shown in order to compete for viewers. They show that with competition, two free-to-air broadcasters would never duplicate a programme type since they

43 We ignore the choices of a licence fee funded broadcaster, both here and in Section 3.4. Apart from the (very weak) constraint of ensuring that viewers do not switch off entirely this mechanism provides no specific incentives towards diversity or quality provision (although a licence fee funded broadcaster which gains revenues from secondary rights, foreign sales and related merchandise may thereby have greater incentives). Incentives arise in relation to the continuation of licence fee funding, where this may be made subject to certain programming commitments. Popularity of programming may also play a role, but for political rather than economic reasons: wide popular appeal might be necessary for the political acceptability of the licence fee.

44 Even if viewers were heterogeneous in their value to advertisers, e.g. due to their socio-economic characteristics or having particular interests related to the advertiser's product, these values would need to be closely correlated with the individual's own valuation of programming for advertising funding to achieve the welfare-maximising outcome. 
would then compete fiercely by restricting advertising, which would eliminate advertising revenues. Relaxing the capacity constraint on the number of channels, Spence and Owen (1977) find that, since a monopolist supplies fewer channels and has the same biases, monopoly provision is worse than competition.

\section{Box 3: Programme diversity under advertising funding}

There are three programme genres, A, B and C. Viewers have exclusive preferences, each consuming only one genre, while intensity of preference is uniform. Total audiences for the three genres number 100, 45 and 30 respectively.

Programme production incurs a fixed cost that is independent of the number of viewers and the genre chosen. Channels are purely advertising funded; advertising revenues are proportional to audience size and independent of genre.

Competing single-channel broadcasters each choose a single genre. If two or more channels offer the same genre, the audience for that type is shared equally between them. In non-cooperative equilibrium each broadcaster selects the genre that maximises its audience given the choices of the others.

Equilibrium choices for markets with different numbers of channels (between two and five) are shown in the table below. The first column gives the total number of channels, and the body of the table shows the number of channels for each genre.

\begin{tabular}{c|ccc}
\hline $\begin{array}{c}\text { No. of } \\
\text { channels }\end{array}$ & $\begin{array}{c}\mathrm{A} \\
\left(\mathrm{V}_{\mathrm{A}}=100\right)\end{array}$ & $\begin{array}{c}\mathrm{B} \\
\left(\mathrm{V}_{\mathrm{B}}=45\right)\end{array}$ & $\begin{array}{c}\mathrm{C} \\
\left(\mathrm{V}_{\mathrm{C}}=30\right)\end{array}$ \\
\hline 2 & 2 & 0 & 0 \\
3 & 2 & 1 & 0 \\
4 & 3 & 1 & 0 \\
5 & 3 & 1 & 1 \\
\hline
\end{tabular}

Duopoly duplicates a single, popular programme genre. With three channels a second genre is served, while five channels are required before all three tastes are met. In the last case viewer preferences are fulfilled but there is duplication of production costs.

Under multi-channel monopoly provision, by contrast, each channel serves a different genre until the point where all three tastes are served (no more than three channels will be offered as this would increase programme costs with no increase in revenue). This outcome is the same as the welfare optimum.

These models assume that programme genres have identical production costs. In reality this is not the case (see footnote 9), and relative profitability of genres depends on profit margins, i.e. advertising revenues (which depend on audience, or 'reach') minus production costs (which do not). For example, drama series attract many viewers but are costly to produce, and so have a low profit margin. ${ }^{45}$ Soaps also attract a large audience but are cheaper to make, so have a high margin. If a cheap quiz show draws the same audience as an expensive period drama, an advertisingfunded broadcaster will not find it worthwhile to spend extra resources on the latter. Thus, in the absence of regulation we would expect high margin programmes-soaps,

$45 \quad$ See Oliver (2005), Figure 7. 
entertainment, movies and national news - to be produced while low margin genresarts and religion, regional programming and current affairs — are largely ignored.

\section{Pay-TV}

With viewers being charged directly, pay-TV is more responsive to their preferences than advertising funded broadcasting. Spence and Owen (1977) compare the two systems in a model with heterogeneous intensity of preferences and unconstrained channel numbers, considering both monopoly provision and competition. They find that, in both systems, programme types with low elasticity of demand (i.e. minority tastes) are under-provided, as are more costly programmes (for a given contribution to total surplus). Pay-TV outperforms advertising funding regarding provision of diversity, due to its ability to take account of intensity of preferences, although it remains biased unless price discrimination between viewers is feasible. With a tight constraint on channel numbers, however, pay-TV may not be desirable since high subscription prices reduce audience size compared with advertising funding.

\subsection{Quality and innovation}

\section{What is meant by programme quality?}

Before discussing quality provision under alternative funding systems it is important to define what is meant by programme quality. Economists regard product $\mathrm{A}$ as being of higher quality than product B if all consumers value A more highly than B. Thus, when offered at the same price, all consumers choose A over B. In other words quality, or 'vertical' differentiation, refers to an agreed ranking over products. By contrast, diversity or 'horizontal' differentiation reflects differences in individual rankings.

In the broadcasting context quality needs to be distinguished from value judgements between genres whereby certain programme types are regarded by some people as being intrinsically more worthwhile or edifying than others-for example, the view that that period dramas are 'quality' programmes while soaps are not. Although it is possible that all viewers have a higher willingness to pay for period dramas than for soaps, audience behaviour when the two are placed head-to-head in free-to-air schedules suggests that this is not the case. Although there may be some agreed rankings across genres, it is more straightforward to think of higher quality as referring to improvements within a genre. It is likely that all viewers would prefer, for example, more spectacular special effects in a movie, better camera angles for a football match, speedier news reporting, more illuminating discussion of current affairs, and so on. ${ }^{46}$ In practice, measuring quality is far from straightforward, ${ }^{47}$ and this has implications for the ability to regulate quality.

46 Ofcom $(2004 \mathrm{~b}, 2005)$ define high quality as 'well funded and well produced'. 'Well produced' would concur with the descriptions given here. 'Well funded' reflects that raising quality tends to increase production costs, thus higher quality programmes typically require greater funding. 


\section{Quality provision}

Higher programme quality typically requires greater production expenditure. For the broadcaster to have an incentive to provide higher quality, it must be able to extract a sufficient proportion of the additional viewer surplus to cover the extra costs. The impact of funding mechanisms on quality provision is examined next; Appendix 1 contains a stylised duopoly model that illustrates some of the results.

With advertising funded television, profitability depends not on how strongly viewers like a programme but only on how many of them watch it. Although higher quality programming draws in more viewers and hence increases advertising revenues, an advertising funded broadcaster's incentive to provide quality depends only on its impact on viewer valuation at the margin, not its effect on infra-marginal viewers. As illustrated by the model in Appendix 1, with a fixed number of channels quality provision is typically too low. ${ }^{48}$ It is possible that advertiser targeting of more affluent viewers, or of those with a greater propensity to spend on advertised goods, might result in some bias towards the viewing preferences of those groups. However, unless these viewers have a particularly strong desire for quality and, in addition, the elasticity of their expenditure with respect to advertising is sufficiently high, this effect is unlikely to guarantee the provision of high quality programmes.

In a pay-TV system part or all of the surplus from higher quality can be extracted from infra-marginal viewers by raising viewer prices. This generates incentives for quality provision, and outcomes at or close to the social optimum can be achieved. In the duopoly model in Appendix 1, where all viewers have the same preference for quality, ${ }^{49}$ a pay-TV operator provides the socially optimal level of quality given its market share. Quality is higher in pay-TV than under advertising funding. Viewer welfare may be higher or lower: in the pay-TV regime viewers pay more, but they view higher quality programmes and fewer adverts. If programme quality is difficult to affect, viewer welfare is higher in a free-to-air regime than in pay-TV.

47 Ofcom (2004a, pp.34-36) examine programming expenditure by genre (in total and per hour), and the change in these amounts over time, and also consider that the amount of original UK production (as opposed to overseas acquisitions or repeats) is a useful indicator of quality. None of these is a robust measure of quality, however: expenditure may be higher, or may increase, for several reasons without raising programme quality, and it is unclear why overseas output should be regarded as being of low quality.

48 An interesting question concerns the relationship between programme quality and the amount of advertising that commercial free-to-air broadcasters are permitted to show. In many countries, regulation constrains the amount of advertising airtime. However, it is plausible that if broadcasters were allowed to show more adverts, they may then choose to provide higher quality programmes. The reason for this is that having more adverts generates higher advertising revenues per viewer, giving broadcasters an incentive to compete harder for viewers, which they do by offering higher quality programmes. Against this must be set the disutility of more frequent or longer interruption by adverts, thus the net effect on viewer welfare is ambiguous.

49 Spence (1975) shows that when consumers differ in their preference for quality, a monopoly firm might choose too high or too low a level of quality, as the ranking of marginal and average value of quality is ambiguous. 
As the number of channels increases, loss of market share per channel reduces quality levels. Hence, other things being equal, more fragmented audiences reduce quality provision. For this reason there is a trade-off between quality and diversity, both of which are desirable to viewers. The optimal number of channels balances the two properties: if excess entry occurs quality is too low and diversity too high, while insufficient entry limits diversity but provides higher quality.

In passing, the conceptual framework in Appendix 1 can be used to shed light on a claim that is sometimes made about the benefits of a public broadcaster: that raising the programme quality of one (regulated) broadcaster forces other (commercial) broadcasters to follow suit. ${ }^{50}$ In this model, at least, the opposite result is found. If the quality of one broadcaster is increased then, all else equal, this decreases the audience of rival broadcasters. Since a pay-TV broadcaster's return to investing in quality is increasing in audience size, this implies that the commercial broadcaster responds by reducing its programme quality. The same point applies if the public broadcaster offers its programmes for free: this decreases the market share that commercial broadcasters can achieve and hence lowers the quality they provide.

\section{Investment in innovation}

Investment in innovation is closely related to quality provision. Whereas quality might often be thought of as deterministic, innovation involves stochastic (unpredictable) improvements. With the return to innovative programmes being risky, the incentive to invest derives from the high returns accruing to successful projects; and the return to success must be sufficiently high to offset the possibility of failure. Hence the ability to gain a high return from successful programmes is crucial for innovation, in broadcasting as in any other sector. ${ }^{51}$

Free-to-air broadcasters cannot directly capture additional viewer surplus generated by a successful programme, and so the incentive to innovate is weak. As noted above, an advertising funded broadcaster's incentive is determined by the impact on the valuation of the marginal viewer rather than viewer surplus as a whole; for this reason innovation, like quality, will be underprovided. Pay-TV, by contrast, stimulates innovation by providing a mechanism through which (high) viewer surplus generated by successful innovation can be captured by broadcasters.

\section{Should people be allowed to watch only what they want?}

Public policy towards broadcasting encompasses concerns that go beyond simply meeting viewer demands as currently expressed. The view has long existed that,

50 For example, while discussing 'competition for quality' Ofcom (2004a) states, '[t]he BBC kept ITV honest; ITV kept the BBC on its toes.'

51 This principle applies to many creative activities. Successful innovators, such as pop stars and best-selling authors, generate very high returns. Commercial backers are willing to take the risk of promoting new artists, and to underwrite the costs involved, because they share in the revenues gained by the successful ones. 
rather than simply 'giving the public want they want', broadcasters should provide the programmes that they ought to watch (for some reason), and withhold or restrict the material that they ought not to watch.

These concerns were stated explicitly in the early days of (radio) broadcasting in the UK, when the idea that a public broadcaster should control what people received was more widely accepted than is it today. John Reith, the first Director General of the $\mathrm{BBC}$, wrote, ${ }^{52}$ 'the preservation of a high moral tone is obviously of paramount importance'; although he conceded that '[t]here is no harm in trivial things; in themselves they may even be unquestionably beneficial, for they may assist the more serious work by providing the measure of salt which seasons.' Ronald Coase remarked that public service broadcasting matched the preferences of some listeners more than others: " $\mathrm{t}]$ hough the programme policy of the $[\mathrm{BBC}]$ gave the lower social classes what they ought to have, it gave the educated classes what they wanted'. 53 Moreover, at this time competition in broadcasting was seen as potentially dangerous since it might undermine the ability of the $\mathrm{BBC}$, through its programme monopoly, to control what was received. ${ }^{54}$

There exist a number of possible reasons for the view that, in the broadcasting sector, merely meeting viewers' current demands is not sufficient to maximise social welfare. The arguments can be divided into two broad rationales:

- viewers do not necessarily choose what it is in their own best interests to watch; and

- television viewing has effects on the wider population, that are not taken into account by the viewer themselves.

In Sections 4.1 and 4.2 respectively we examine the possible arguments in each case.

\subsection{Do viewers make the 'right' decisions for themselves?}

Textbook economics assumes that the consumer is able to assess the contribution of each of the available goods to her utility and make the choice that maximises her own welfare. However, this ability may sometimes be less than perfect. There are three

52 These quotes are from 1924 and 1925. See Coase (1950), page 47.

53 Coase (1950), page 177.

54 The BBC used this argument to protect its position when it was threatened with competition from wire broadcasting (a relay exchange system) in the 1930s, stating, '[t]he system ... contains within it forces which uncontrolled might be disruptive of the spirit and intention of the BBC charter'; see Coase (1948). The BBC view gained support from elsewhere: a Times leader article published from around that time, quoted in Coase (1950), argued, '[w] hat is certain about the relay system is that, under present conditions, it will spread both widely and rapidly among the poorer classes of the population; and this country will not for long be able to congratulate itself on a broadcasting system under which, while broadcasting is controlled with enlightenment and impartiality by a responsible public corporation, the listening is controlled by Tom, Dick and Harry.' 
reasons why the consumer's choice may sometime fail to achieve the best outcome for herself:

- experience goods: the consumer's utility function is fixed, and represents what is in her own best interests, but she cannot determine all of the relevant characteristics of the good prior to consumption. The consumption experience reveals these characteristics, allowing subsequent decisions to be based on better information;

- merit goods: characteristics of the good are known in advance of consumption, but the consumer's utility function is not fixed. When a previously untried good is consumed, preferences change such that greater utility is derived from its future consumption; and

- paternalism: the consumer's utility function may not represent what is in her best interests, thus utility-maximising choices do not necessarily maximise her welfare.

We start by discussing the arguments surrounding experience and merit goods, then turn to possible justifications for paternalism.

\section{Experience and merit goods}

It is likely that there are elements of both experience and merit goods in television programming. The attractions of a new series are not entirely apparent prior to viewing - whether a new comedy will be amusing, for example - and certain tastes develop only with experience. However, these features are true of many other goods, including restaurant meals, music albums and leisure activities. It is unclear why they are deemed (by some) to be so problematic as to justify intervention in broadcasting, but not in other sectors.

Moreover, although more complex than the standard case of a fully informed consumer exercising a static utility-maximising choice, rational decisions regarding both experience and merit goods can be taken by consumers. A hypothetical rational consumer anticipates that trying a new product might cause her assessment of its value to go up, either because her knowledge of its characteristics improves (experience goods) or because her own tastes are developed by the experience (merit goods). Taking potential future benefits into account, she will consume the good. In addition, consumers frequently learn about product characteristics and the possibility of developing new tastes from the experiences of others: this diffusion process works well for restaurants, holidays and sporting activities, and surely also for television programmes.

It might be argued that the consumer could be short sighted and ignore, or fail to realise, the fact that his tastes or knowledge may change as a result of actions within his own control. For anyone with a reasonable level of experience, however, this would imply that he disregards, or perhaps forgets, similar experiences of learning 
and development in the past; the former would be irrational, while the latter seems implausible. Of course, trying out a new product involves some risk: consumption might turn out not to be desirable after all. But this needs to be balanced against the possibility of higher utility in the future. In this sense sampling is similar to other forms of investment: the consumer incurs a cost now (by consuming a product that does not maximise immediate utility) for the prospect of an attractive return in the future (consumption of the product when it yields high utility). Consumers are capable of undertaking such decisions in other dynamic contexts; and moreover, the impact of a poor viewing selection would seem to be rather less severe than a bad choice of mortgage or pension, for example.

Commercial suppliers have an incentive to facilitate learning and the development of new tastes, e.g. through promotions and introductory offers, since they benefit from higher future consumption. To encourage sampling a broadcasters adopt a number of strategies: launch a series on a free-to-air channel then move it to pay-TV; show short excerpts of a programme as a trailer; or (with pay-per-view) levy the charge after a portion of the programme has elapsed. ${ }^{55}$ The broadcaster could also build a reputation for high quality programming, increasing viewers' confidence in them and making them more likely to purchase its programmes in the future.

Even if there were a case that experience and merit goods are particularly prevalent in broadcasting, and that these problems cannot be overcome as described above, the idea that a broadcaster can make optimal decisions for them is implausible. ${ }^{56}$ Viewers are heterogeneous, and both the actual preferences and potential tastes of a large number of individuals would need to be assessed. Note that, in the case of merit goods, since what is at issue are tastes that are not yet developed, viewer surveys will be uninformative. Nevertheless, merit good arguments are often put forward as a justification for directing public broadcasters to provide 'challenging' programmes and to stimulate rather than follow viewer tastes. ${ }^{57}$

\section{Paternalism}

The paternalistic view is that (some) people are unable to take decisions that are in their own best interests and that, left to their own devices, they will fail to achieve the optimal outcome for themselves. In economic terms this implies either that the consumer is for some reason unable to take actions that maximise his utility, or that

55 Note that the last two mechanisms can be used for a single programme that is not part of a series, as for movies.

56 Coase (1966) expresses scepticism about the ability of a public broadcasting authority to determine which programmes should be broadcast in the best interests of viewers. Referring to the UK's 1962 Pilkington Report on Broadcasting, he states, "[ $\mathrm{t}$ ] he committee avoids the question of how it should be decided which programs to transmit and for the phrase "what the public wants," they substitute another and better, "what the public authority wants." What the public authority should want, how it would get the information which would enable it to do what it should, and how in practice it would be likely to act are questions which all disappear in a cloud of pious platitudes.'

57 See Coase (1966) for quotes from early public reports and Ofcom (2005) for a recent example. 
his utility function, both now and in the future, does not represent his true welfare. Even if this were the case, for intervention to make sense it must also be believed that the public authority (here, a public broadcaster or regulator) is able to make better decisions and get closer to achieving consumer welfare.

As illustrated by the quotes above, Reithian broadcasting was based on a heavy dose of paternalism with the public broadcaster providing programmes that people ought to watch, rather than simply those they wanted to watch. Today, the idea that a public broadcaster or government agency knows better than viewers themselves what is good for them, and should exert control over what they watch, gains less acceptance. Moreover, a centrally-controlled broadcasting system is open to the risk of bias towards material that the government wants people to see, rather than that which it is in their best interests to watch.

Nonetheless, paternalism remains evident in controls on the broadcasting of harmful and offensive material, such as violent or sexually explicit scenes, even now that encryption can be used to prevent unintentional viewing of such material and thus restrict it to those who have chosen to watch. ${ }^{58}$ A significant degree of paternalism quite naturally exists in relation to children's viewing. Many parents express concern about the programming that their children are exposed to, as well the total time spent viewing, and wish to exert some control over this. Wider public concerns have also been raised (e.g. by the UK government and various agencies) over areas such as food advertising to children. This debate presumes that children (in particular) are not capable of making wise choices about what is good for them, and that there is a public, as well as parental, obligation to protect them.

\subsection{Wider impacts of television viewing}

A number of arguments for intervention in broadcasting arise from externalities associated with television viewing. That is to say, if large numbers of people view certain kinds of programmes, this affects the wider population in some way that the viewers themselves do not take into account. An externality may be either positive, generating external benefits, or negative, causing detriment elsewhere. In the presence of positive externalities the market level of consumption is too low from the social perspective; with negative externalities consumption is too high. In either case measures which induce something closer to the socially optimal outcome are justified, as long as this benefit outweighs the cost of intervention.

In this section we examine various external effects of television viewing that have been cited by commentators, starting with positive externalities before then turning to negative ones.

58 See Camerer et al. (2003) for an economic argument in favour of certain forms of paternalism. 


\section{Positive externalities}

A number of positive externalities have been claimed for television broadcasting:

- educational benefits;

- network externalities (the 'water cooler' effect); and

- social or 'citizenship' benefits.

That there may be educational effects of television viewing, and external benefits generated by education, is uncontroversial. As well as providing directly educational material (such as schools programming), television can be a powerful medium for providing information about, and stimulating interest in, a variety of topics - ranging from science and technology to history and languages - that can be broadly defined as educational. As with formal types of education this benefits the economy through the creation of a more educated and productive workforce. There may also be direct benefits to particular individuals; for example, if information gathered from watching a medical drama is used to administer life-saving first aid. Since these benefits are quite diffused, they are unlikely to be internalised by market participants and there is a serious prospect that educational programming will be underprovided.

The role of television viewing as a common experience that people discuss 'around the water cooler' might be regarded as a form of network externality. To the extent that these discussions raise enjoyment of viewing commonly watched programmes, there may be a positive externality between the viewing behaviour of different individuals. But the creation of widely known brands through 'water cooler' discussions is commonplace for market-driven products such as pop music, sports teams, novels and Hollywood movies; it is unclear why the existence of such an effect justifies intervention in broadcasting. Mechanisms exist to internalise such externalities: viewers themselves may coordinate their viewing as benefits flow in both directions; meanwhile broadcasters, as beneficiaries of greater uptake, have an incentive to create popular and distinctive programmes that stimulate discussion. Although difficult to quantify, it is unlikely that (uninternalised) effects of this kind are of great importance.

The 'water cooler' effect has also been mentioned as a forum for shared experiences that in turn generate other social benefits. In this view it is not the effect itself but rather its wider behavioural implications that are an externality. For example, Brookes (2004) highlights the role of television in building 'social capital' by improving understanding and building trust between people through shared experiences. However, as noted above, there is little reason to suppose that the mechanism itself will break down under market provision of television. Moreover, there is some irony in highlighting as a mechanism for promoting social cohesion a medium that is also much criticised for contributing to greater isolation and reducing 
participation in community activities. ${ }^{59}$ (Negative effects of television viewing are examined further below.)

There is also the currently popular notion that television is an important medium for building 'citizenship'. The most obvious aspect of this is that accurate reporting of news and current affairs can help create a well-informed citizenry who can adequately discipline government and other powerful interests, to the benefit of all. The role of the media, especially television, in the political process is the focus of current research. $^{60}$ However, empirical evidence concerning the impact of television on political involvement is mixed. Prat and Strömberg (2004) find that the introduction of commercial television in Sweden in 1990 raised voter turnout. Gentzkow (2004), however, finds the growth of television to have had a negative impact on voter turnout in the US, perhaps by inducing substitution away from other media (such as newspapers) which carry more political coverage.

Moving beyond political involvement, it is sometimes argued that people become more community-oriented, or more tolerant, as a result of watching certain behaviour on television. However, a direct link between the messages and representations in television programmes and viewers' own behaviour is highly contentious, with little clear evidence. Moreover, even if such a link exists, this must be placed alongside the isolating effect of television noted above. All in all, it is highly unclear that television should be promoted as a means of inducing people to be more community-spirited.

\section{Negative externalities}

There are a number of negative externalities associated with television viewing. Quite apart from the possibility of undesirable behavioural responses to particular broadcast content - just as for positive attributes, the link between violence portrayed on television and violent behaviour is controversial - there are a number of reasons to discourage heavy television viewing.

It is sometimes argued that many people spend too much time watching television, from both an individual and a social perspective. On average, each individual in the industrialised world watches television for about 3 hours every day. Among concerns regarding the sedentary nature of modern life, television viewing is a significant contributing factor. Children's viewing habits in particular are a cause for concern: watching television has been found to lower a child's metabolic rate, reduce physical

59 Putnam (2000, page 217) provides an apt quote from T.S. Eliot, who in 1963 wrote that television 'is a medium of entertainment which permits millions of people to listen to the same joke at the same time, and yet remain lonesome.'

60 In these models, media affect political outcomes through a variety of routes: by building (or destroying) a politician's reputation; through monitoring of politicians' actions; and by enhancing the salience of particular issues at the ballot box. For example, based on the premise that politicians deliver policies that favour informed voters, Strömberg (2004a, 2004b) examines the media's role in this process as the provider of information. Besley and Prat (2004) examine the role of press freedom; in this analysis, features of the media industry determine the government's ability to capture the media and to control political outcomes. 
exercise and invite over-eating (especially when combined with tempting adverts for junk food). Spitzer (2005) argues that television impairs a child's ability to learn and to concentrate. He also estimates that viewing habits and resulting obesity lead to the premature death of around twenty thousand Germans each year.

Putnam (2000) summarises various studies about viewing habits, and factors that are correlated with them. For instance, he documents a strong correlation between heavy viewing and various indicators of anti-social behaviour (such as the number of letters written to friends, 'giving the finger' to another driver, etc.). Although one would rightly hesitate before inferring any direction of causality-socially isolated individuals might turn to television to fill their time-Putnam also reports the findings of a number of 'natural experiments' where local communities were suddenly able to receive television signals. Field observations indicated a causal link between the introduction of television and the subsequent reduction in community activities.

In its early years, it was hoped that (radio) broadcasting might enliven national life by stimulating other activities. William Haley, then Director General of the BBC, wrote in 1947 that, ${ }^{61}$

'[The public service broadcaster] does not want people to be listening all the time ... For broadcasting will not be a social asset if it produces a nation of listeners. ... If it cannot give to literature more readers than it withholds, it will have failed in what should be its true purpose. Its aim must be to make people active, not passive, both in the fields of recreation and public affairs.'

Viewed from today, this ambition would appear to have been over-optimistic.

\section{Intervention to mitigate externalities}

While there may be disagreements about the source and scale of externalities, there is a coherent rationale for intervention in the broadcasting market to promote those programmes generating positive externalities and to diminish those with negative externalities.

To diminish the negative aspects, broadcasting standards could be imposed to restrict the broadcasting of harmful or inappropriate programming. ${ }^{62}$ In relation to children, measures might be adopted to facilitate parents' efforts to control their children's viewing, such as clear programme labelling and time-of-day controls (e.g. the UK's 'nine o'clock watershed', before which the broadcasting of programmes unsuitable for children is not permitted).

Regarding positive externalities, intervention may be desirable to increase the provision of socially beneficial programming. For example, subsidies for educational

61 See Coase (1950), pages 175-176.

62 Note that, to be effective, these measures must apply to all broadcasts, not just public service channels. In a multimedia world it might seem desirable to extend similar standards to other media, such as the Internet, but such controls would be wide-ranging and difficult to enforce. 
material may be justified. Provision may be increased by means of obligations imposed on designated public service broadcasters, or by giving inducements to all broadcasters to show such programmes. However, in order to generate their desired effects it is crucial that these programmes are actually watched, not just that they are broadcast. We turn to this issue next.

\subsection{Will people watch what we want them to watch?}

In principle, consumption of a product can be increased by reducing its price. In broadcasting, however, individual programmes are typically viewed as part of a channel and once a subscription has been taken out, or in any case if it is broadcast free-to-air, the incremental price for watching any programme is zero. With many attractive programmes available for free at the margin, a negative price (i.e. a payment to the viewer) might well be required to increase consumption of socially beneficial content to the optimal level, especially if does not directly appeal to the viewer's own tastes. It is difficult, however, to come up with an effective system to make payments for watching. ${ }^{63}$ The price mechanism therefore seems inadequate as a means of inducing people to watch 'what we want them to watch'.

Broadcasters have strategies which exploit viewer behaviour to increase the audience for less popular programmes. If viewers tend to remain tuned to the same channel at the end of a programme, it may be possible to retain their attention for less gripping material by scheduling this between more popular shows (known within the industry as 'hammocking'). However, as viewers increasingly switch around between an everexpanding range of channels, the less effective this strategy becomes. ${ }^{64}$

Ultimately, a more effective approach might be to include PSB messages within popular programmes, analogously to the 'product placement' strategy of advertisers. This might include, for example, first aid techniques demonstrated during medical dramas, or instances of racial tolerance occurring within the story lines of popular soaps. The view that by tackling difficult social issues in a responsible manner, soaps such as EastEnders are 'providing an important public service' might be interpreted as advocating something similar to this. ${ }^{65}$ An historical instance of the strategy of conveying public information messages through popular entertainment is the longrunning Radio 4 drama series, The Archers, originally conceived as a way of keeping farmers informed on best practice. ${ }^{66}$ As a means of catching viewers' attention in a

63 In particular, whether someone has watched, and done so attentively, is unverifiable.

64 Ofcom (2004a) reports that even in analogue terrestrial homes, viewers typically watch at least three of the five channels over the course of an evening. (Supporting documents, Vol. 1 Part 4).

65 From an interview with Tessa Jowell, the UK Secretary of State for Culture, Media and Sport. See The Independent, 'Watching with Tessa', 2 March 2004.

66 When The Archers was first broadcast in 1950 it was hoped that, although farmers would listen for the stories, they would along the way pick up messages to help them increase production at a time when Britain was still subject to food rationing. In fact its educational purpose far outlived rationing, continuing until 1972. 
multi-channel environment this strategy could become the most, even the only, effective technique, although care must be taken not to undermine the popularity of a show by overloading it with 'worthy' messages and losing its original appeal.

\section{Provision of public service broadcasting}

Supposing that some form of intervention in broadcasting content is desirable, say to increase the provision of programmes generating educational benefits, how is this to be achieved? The term 'public service broadcasting' encompasses a range of systems and institutions. This section describes and assesses the main options available to policymakers.

To be effective, public service broadcasting needs to achieve two purposes. First, the relevant types of programmes (say, those with educational content) need to be produced and made available to viewers through broadcasting. Secondly, as explained in Section 4.3, people must be induced to watch them. Since the aim is to satisfy social purposes beyond the viewer's own preferences, it cannot simply be presumed that uptake will be sufficiently high to achieve the social optimum.

Two broadly-defined systems for providing PSB may be distinguished; in each case the broadcasters may be commercial companies or public bodies (or a combination of the two):

- Licensing: public service broadcasters are obliged to meet certain programme requirements as conditions of their licence to operate; or

- Commissioning: public service programmes are commissioned from producers and broadcasters using contestable funding. ${ }^{67}$

We examine the two types of system in turn.

\section{Licensing of public service broadcasters}

Under a licensing system, public service obligations are imposed on broadcasters as conditions of their licence. An easily specified and limited obligation would be to require a certain amount of airtime to be devoted to news coverage during peak hours. A more wide-ranging intervention might be to require certain minimum amounts of specified types of programming (e.g. of different genres, or with certain educational content). Quality requirements might be stated, although what is meant by quality is subjective and difficult to specify making this intrinsically harder to regulate. A similar problem applies to innovation.

Programme obligations (beyond what the commercial market would anyway provide) are costly to broadcasters, either directly (by increasing production costs) or as an opportunity cost (by requiring less popular, and hence less profitable, programmes to be shown). Their sustainability depends on two factors: the method of revenue

67 Programme commissioning is used in New Zealand and Singapore. 
generation used and whether or not the number of channels is constrained. If licence fee funding is used then, in principle at least, its level can be set to match the cost of the obligations. With advertising funding or pay-TV, obligations are sustainable as long as broadcasters can generate sufficient revenues to cover the costs incurred. While the number of channels is tightly constrained due to spectrum scarcity, the high rents that accrue to commercial broadcasters ${ }^{68}$ can be used as an implicit form of funding, cross-subsidising public service obligations. Without spectrum constraints, competition between channels eliminates scarcity rents. Public service obligations must then either be reduced so as not to undermine these broadcasters' viability, or imposed on all broadcasters so that even with entry (which will then be more limited) costs can still be covered. Alternatively, direct funding of public service obligations, from a licence fee or general taxation, could be used.

A regulator must specify licence obligations, monitor compliance and determine the renewal or reallocation of licences. The burden of regulation increases with the complexity of licence terms and the number of licensees. If licences are granted for a lengthy period (e.g. for several years at a time) the incentive for compliance is weak: the ultimate penalty for failure to meet programming obligations is licence withdrawal, but this is a distant (and sometimes implausible) threat.

\section{Commissioning of public service programmes}

In a commissioning system, funds from a licence fee or taxation are used to finance programme commissions. In principle, programmes may be sourced from any producer (including independent production units) and broadcast on any channel, either purchasing the programme and the broadcasting slot separately or procuring them together from a vertically integrated broadcaster. Competitive tendering mechanisms provide incentives for efficient production and minimise acquisition costs: competitive bidding will drive subsidies down to the difference between production cost and revenues gained from elsewhere (e.g. from advertisers), not the full programme cost. Moreover, with frequent commissions repeated interactions stimulate producers to build and sustain a reputation for delivering high quality.

Although the focus of recent attention, ${ }^{69}$ the idea that broadcasters might compete for public funds is not a new one. In 1936 the Economist, quoted in Coase (1950), asked: 'is it really necessary to choose [between the American and British systems]? Could not the merits of both systems be combined? ... Let the State continue to collect the licence, let it, if you will, own the actual transmitting stations. But let the

68 Indeed, the phrase 'a licence to print money' was coined when the licences for ITV, the first commercial television channel in the UK, were awarded in 1955. Funding from spectrum rents has been a major building block of PSB in the UK over the past 50 years; see Section 8 .

69 A competitive commissioning system has been advocated in the UK by Elstein (2004) and Peacock (2004). In January 2005 the government-appointed Burns panel recommended the creation of an independent Public Service Broadcasting Commission (PSBC) with, among other powers, the ability to award some licence fee funds to broadcasters other than the BBC. The government did not follow this recommendation in its subsequent Green Paper, DCMS (2005). 
programmes be provided by two corporations, say the $\mathrm{ABC}$ and the $\mathrm{BBC}$, competing with each other. They should share the licence revenue and the listener might even be permitted to distribute some very small fraction of his ten shillings as a mark of favour the corporation which he considers the better.'

A commissioning body or 'Arts Council of the Air' would be needed, to call for tenders or specify areas within which programmes are invited, assess competing bids and award contracts. Multiple commissioning bodies might be used: ${ }^{70}$ this could introduce competition (or at least benchmarking) into the commissioning activity itself, and help prevent good projects from falling through the net. Alternatively there could be specialisation in the commissioning process, with separate bodies for music, the sciences, and so on. Moreover, a system with multiple commissioning bodies would be less susceptible to capture by a particular broadcaster or interest group.

In either a licensing or commissioning system, requirements must be determined with a view to the ability to attract viewers, both when devising commissions or licence obligations, and in selecting broadcasters. Innovative formats and non-traditional broadcasters may be effective in reaching new audiences, especially those that are traditionally harder to reach. ${ }^{71}$

\section{Public service broadcasting in the analogue era}

We now draw on the analysis set out above to examine the rationale for, and provision of, public service broadcasting. First, in this section, we consider the traditional analogue environment; then, in Section 7, we turn to the digital world. Technological developments are a crucial part of this, so each section starts by briefly describing the relevant features. We examine the applicability of market failure and 'citizenship' arguments for intervention given those characteristics, drawing out implications for the nature and scope of PSB. Finally, we consider the means by which public service broadcasting might be provided in each setting, and its relative effectiveness.

Analogue terrestrial broadcasting is characterised by two key features:

- spectrum constraints limit the number of channels, and broadcasters earn scarcity rents since returns cannot be driven down by free entry; and

- non-excludability of viewing requires programmes to be broadcast free-to-air, eliminating subscription as a means of generating revenue. ${ }^{72}$

70 Funding of medical research would be a good analogy for this, with (in the UK) the Medical Research Council, Wellcome Trust, European Union and numerous charities each offering funds.

71 Prat and Strömberg (2004) found that commercial television was more effective than the public broadcaster in raising viewers' knowledge of political matters and raising voter turnout, especially among (harder-to-reach) younger and less-informed viewers.

72 Cable connection can be denied to non-payers, and satellite services can use encryption for analogue as well as digital services. These platforms are excluded from our analysis as they have only recently been developed in the UK. 
Since commercial broadcasters are unlikely to have access to licence fee funding, ${ }^{73}$ in practice the second feature implies that advertising is their sole source of funds. Thus, under analogue broadcasting a market system would consist of just a small number of advertising-funded broadcasters. Drawing on the analysis in Section 3 it can be seen that the outcome of such a market would fail to meet the demands of television viewers in a number of respects; clearly, a 'market failure' rationale for PSB exists in analogue broadcasting:

- diversity of programming is insufficient, with broadcasters duplicating popular genres rather than serving niche tastes;

- quality of programming is too low;

- innovation incentives are poor; and

- airtime devoted to advertising tends to be excessive, especially if its nuisance cost to viewers is high.

Added to this, there are wider concerns beyond the viewer's own preferences that may justify some form of intervention. Although arguments that viewers fail to make the best choices for themselves do not seem sufficiently strong to merit intervention in the generality of cases, a more paternalistic approach towards children may be justified. With all channels broadcast free-to-air, it may be necessary to prohibit certain types of unpleasant material to prevent unintentional viewing. While disagreements exist over the precise sources and magnitude of externalities, wider social and educational effects of television provide a coherent rationale for intervention to increase provision of programmes generating positive externalities and diminish those with negative externalities.

To summarise, in the analogue context an appropriate system of PSB would be designed to:

- provide programmes catering for niche interests which would otherwise be left unserved;

- stimulate higher quality and innovation in programming;

- limit the amount of airtime given over to advertising (if this can be done without further weakening broadcasters' incentives for quality provision);

- restrict the broadcasting of harmful material, and protect children; and

- promote the provision and viewing of socially beneficial programmes, such as those containing educational material.

Most of these purposes can be seen in existing systems of public service broadcasting, including the UK's. A case study of this system is given in Section 8.

73 A group of equipment manufacturers could perhaps add a surcharge to sales of television sets to fund broadcasting services, as was initially the case for radio in the UK, but competition between suppliers would undermine this. In practice government support is necessary for enforcement of a licence fee. 
Turning to provision, rents resulting from spectrum constraints can be used as an implicit source of funding for costly public service obligations (via a licensing system), reducing the need for direct government subsidy or a (higher) licence fee. A further implication of spectrum constraints is that the viewer faces a limited choice of channels. If public service broadcasters account for a high proportion (perhaps even all) of these channels, they can largely determine what people watch. Historically, in the face of limited competition, socially desirable but less popular programmes have nonetheless been able to gain a reasonable audience.

\section{Public service broadcasting in the digital world}

The adoption of digital technology, with related developments, fundamentally alters the characteristics of television broadcasting. Specifically the following technological changes, often referred to under the umbrella term of 'digitisation', are taking place:

- digital compression techniques allow many more channels to be broadcast for a given spectrum allocation, greatly relaxing the constraint on the number of channels; $;^{74}$

- conditional access systems facilitate the exclusion of unauthorised viewing, ${ }^{75}$ making subscription funding feasible; and

- personal video recorders (PVRs) give the viewer far greater control over the timing and content of television viewing.

Moving to pay-TV, especially when combined with a huge expansion in the number of channels, greatly mitigates the market failures arising under advertising-funded broadcasting. Since viewer surplus can be extracted, commercial broadcasters have an incentive to deliver a diverse range of programmes, with quality appropriate to viewers' willingness-to-pay. ${ }^{76}$ Fewer adverts are shown in pay-TV; ${ }^{77}$ moreover, if the use of PVRs becomes widespread this will undermine advertising as a source of funding and further reduce the number of adverts shown, perhaps to a level that is too low from a social (and viewers') perspective, as shown in Appendix 1. Viewer

74 Depending on spectrum allocation, digital terrestrial transmission (DTT) allows several dozen channels to be broadcast, while digital satellite and cable platforms can support a few hundred. Although demand growth might eventually alter this conclusion if technological improvements do not keep pace, spectrum availability is no longer a binding constraint on channel numbers.

75 Although pay-TV piracy through copying of smart cards may sometimes be a problem, this can be overcome by periodically issuing new smart cards to subscribers, and improving encryption software.

76 A sceptic might argue that the current state of pay-TV in the UK is evidence against this claim. However, caution should be exercised in forming judgements about the output of a fully commercial broadcasting market based on the existing pay-TV sector, as the presence of a statefunded, sometimes high-quality broadcaster — namely, the BBC — greatly diminishes a commercial broadcaster's incentive to supply high-quality programming.

77 Interestingly, digital television is witnessing the emergence of shopping channels such as QVC whose primary purpose is advertising and that are watched for this reason. Like advertising-only newspapers, the use of such formats may increase as these become a more effective means of reaching potential viewers than traditional advertising methods. 
charging can be implemented in ways that minimise exclusion of desired viewing, using pricing techniques such as bundling and windowing.

The move to pay-TV might raise certain access issues. Charging may mean that some viewers watch a more limited number of channels than if all were broadcast free-toair. Although this is largely a matter of individual choice, and some of the programming would not have been produced anyway without the ability to charge viewers, distributional concerns might be raised. For example, with its ability to capture viewer surplus, pay-TV can outbid free-to-air broadcasters for popular sports rights (although this may be mitigated by other benefits to football clubs from retaining some amount of free-to-air coverage). For this reason, in the UK certain sports events deemed to be of national importance are 'listed' to restrict the acquisition of exclusive pay-TV rights and ensure wide public access to them. ${ }^{78}$

In the digital world, viewer sovereignty in the marketplace largely removes the 'market failure' basis for PSB, as the unregulated market will give people broadly what they want to watch. This does not necessarily imply that there is no basis for intervention, however. We saw in Section 6, for the case of analogue broadcasting, that there are arguments for controls on the broadcasting of certain types of harmful material, and increasing the provision of programmes which generate wider social benefits. These arguments do not disappear with digitisation, although some changes might be possible.

Enhanced viewer control, resulting from encryption and PVR use, allow individuals to avoid seeing unwanted material. These technologies can also assist parents in controlling what is seen by children. If these protections are deemed adequate it might be possible to relax existing prohibitions on the broadcasting of certain material, as long as this is shown only on encrypted channels (perhaps with PIN protection) and clearly labelled as to its nature. ${ }^{79}$ Where significant negative externalities arise, however, an outright ban would probably still be justified.

There is little reason to suppose that the magnitude of positive externalities alters significantly with digitisation. It is possible that market provision of some types of socially beneficial programmes will increase, to the extent that these are favoured by minority tastes that will now be served. Even so, market under-provision of socially beneficial programmes remains very likely and some form of intervention to increase its supply may be desirable.

However, following digitisation the question of whether people will actually watch socially beneficial programmes becomes a critical one. In its early, monopoly days the BBC could effectively force viewers to watch the programmes it thought they should, since the only alternative was to switch off. The introduction of competition

78 See Hansen and Kyhl (2001) for an analysis of the effects of this system.

79 Although in its 2005 Broadcasting Code, Ofcom decided that such measures would be inadequate to protect children and maintained the prohibition on R18-rated (i.e. pornographic) material. 
from commercial television reduced the BBC's control, but while the number of channels remained limited the audience for public service material held up fairly well.

In the digital world the availability of a huge range of competing channels with electronic programme guides (EPGs) to assist selection, together with the introduction of PVRs, increases enormously the ease with which the viewer can switch channel, or skip some part of it, as soon as less appealing content comes on. When presented with so much attractive material viewers may exercise this choice by choosing entertainment over more challenging and educational material. ${ }^{80}$ In this environment socially beneficial programmes may struggle to gain attention: even if we think it is desirable that people should watch more, or higher quality, news than they would do if left to themselves, there may be little that can be done about this. As Richard Eyre, then Chief Executive of ITV, succinctly put it: ${ }^{81}$

'Free school milk doesn't work when the kids go and buy Coca-Cola because it's available and they prefer it and they can afford it. So public service broadcasting will soon be dead.'

Unlike the Reithian era, the idea that competition should be held back-if this were even possible - so that viewing can be directed towards public service programming would not gain acceptance today. With no realistic scope for reducing commercial competition, alternative means of promoting the uptake of public service content must be found if the system is to be continued. As described in Section 4.3, this might utilise methods akin to 'product placement'; but there are limits to how far this can be taken without undermining a programme's appeal. Whatever their desirability, if positive externalities cannot, in fact, be realised then these constitute a weak basis for public intervention. With the 'market failure' rationale largely removed and growing difficulties in getting people to watch 'what we want them to watch', the likely outcome is that (aside from controls on harmful material) public service broadcasting will indeed soon be dead.

\section{Provision of public service broadcasting in the digital world}

On the assumption that some level of intervention to increase the provision of certain types of programming is nonetheless desired, we next examine the implications of digitisation for the funding and delivery of PSB.

80 Ofcom (2004a) reports that more serious and challenging programmes are most affected by multichannel competition, with their share of viewing more than $50 \%$ lower in multi-channel homes compared with those having analogue terrestrial channels only (see Ofcom 2004, Figure 28). However, being a contemporaneous comparison between self-selected groups these data suffer from selection bias and are likely to overstate the magnitude of any change in behaviour by individual households when faced with a greater choice of channels. The fact that as multichannel TV has grown (entertainment-focused) BBC1 and ITV1 have experienced large falls in viewing share while (more factual and culture-based) BBC2 and Channel 4 have held up relatively well, indicates a significant selection effect. See Ofcom (2004a), Figure 22; BARB data for a longer period show trends stretching back to the launch of pay-TV in 1991. 
Following digitisation and the relaxation of spectrum constraints, channel entry intensifies competition and eliminates the scarcity rents of incumbents. Whatever the source of revenue, commercial broadcasters' profits fall as audiences fragment. ${ }^{82}$ Advertising revenue is additionally threatened by the use of PVRs to avoid adverts. Unless spectrum availability is artificially constrained, gifted spectrum can no longer confer sufficient value to fund expensive programming requirements. Onerous PSB obligations imposed on commercial broadcasters become unsustainable, threatening the survival of a broad system of provision that includes commercial as well as public broadcasters. If commercial broadcasters are to participate direct subsidies will be required, and these must be funded out of general taxation or by 'top-slicing' the licence fee revenues currently granted to public broadcasters.

The licence fee, unlike advertising revenue, is immune to commercial pressure. However, as a compulsory charge on all TV viewers, it is subject to constraint of popular acceptability. This is likely to be threatened in the digital world, for two main reasons. First, the growing use of broadband, and even mobile phones, for video streaming blurs the distinction between the television set and other devices, rendering a licence fee that applies to one but not the rest increasingly arbitrary. Extending the licence fee to these areas, however, is likely to be politically unpalatable and difficult to enforce, making its abolition the more likely outcome. Secondly, while the licence fee is acceptable to most people when the programmes it funds constitute the major part of their viewing, ${ }^{83}$ this support is likely to fall in line with the viewing share of the public broadcaster (and as increasing numbers also subscribe to pay-TV). Ofcom reports that ' $[\mathrm{t}]$ he TV licence fee is already questioned by viewers whose use of the BBC's services is declining, ${ }^{84}$ while survey evidence suggests that the majority of viewers regard the licence fee as no longer justified in a multi-channel environment. ${ }^{85}$ As Gavyn Davies predicted a few years ago: ${ }^{86}$

'the digital age will increasingly be one in which many or most consumers of television pay for packages closely tailored to their needs. As they become more accustomed to choice, to subscription and to pay-per-view, it could be that the licence fee will come to seem an anachronism.'

If correct this analysis implies that the licence fee as well as commercial funding of PSB is undermined in the digital world. Funds might instead be provided out of

81 MacTaggart lecture at the Edinburgh International Television Festival, 27 August 1999.

82 Ofcom (2004a) reports that the most popular programmes on analogue terrestrial in the UK could expect audiences of some 16-17 million viewers in the late 1990s, but by 2003, 14 million was a typical ceiling.

83 Although the need to retain public support by giving them entertaining programmes creates some tension with PSB objectives.

84 See Ofcom (2004a) page 8; also Figure 44.

85 A YouGov poll conducted for the Telegraph in October 2002 showed that 58 per cent of those surveyed believed the current system to be no longer justified in a multi-channel world. (The Telegraph, 'Unwanted licence fee', 28 October 2002.) 
general taxation, although this too requires political support and in practice the amount involved is likely to be much more limited. If multiple providers are to be retained, public funds must be made available to commercial as well as public broadcasters, perhaps through a competitive commissioning system.

\section{The scope of public broadcasters}

A further problem arises from the blurring of the boundary between the activities of public broadcasters and those of commercial operators. In an analogue setting where purely commercial broadcasters would fail to generate the kinds of programmes that viewers desire, the role of public broadcasters in fulfilling viewer demands was uncontroversial. But now that the commercial sector is capable of meeting these demands, the activities of public broadcasters are increasingly in conflict with this. With licence fee funding given to public broadcasters alone, commercial broadcasters complain of unfair competition and crowding out. Whether this is detrimental to welfare depends on the relative efficiencies of the broadcasters and the attractiveness to viewers of their respective services, but the distortion of competition is likely to generate some inefficiency.

To tackle this problem, a tighter definition of the role of public service broadcasters, limiting this to areas that the commercial sector would not otherwise provide, is advisable. Licence fee funds (if the licence fee is retained) would also need to be ring-fenced, and potentially made available to other broadcasters if they produce programmes to fulfil public purposes.

\section{Public service broadcasting in the UK}

As a case study, we describe the system of public service broadcasting in the UK. This regime was developed in the analogue era, with its origins dating back to the 1920s (initially for radio broadcasting). It now faces pressure from digitisation: many households have already adopted digital television, and digital switchover (i.e. turning off the analogue signal) is due to be completed by the end of 2012.

The section has two main parts: first we describe in detail the purposes stated for PSB in the UK and its current system of provision, relating these features to the analysis of Section 6. Secondly, we discuss threats to the future sustainability of this system with the onset of digital broadcasting.

\subsection{The UK's public service broadcasting system}

The purposes of the UK's brand of public service broadcasting are defined under the Communications Act 2003 (hereafter 'the Act'). Section 264(4) of the Act provides general statements of purpose, while detailed elements are specified in Section 264(6). The full text of the latter is set out in Box 4. In addition to the kinds of public

86 Davies (1999), Section 5, page 144. 
service obligations described in this chapter, the remit includes an element of national and regional industrial policy; see Section 264(6)(j). ${ }^{87}$

\section{Box 4: PSB under the Communications Act 2003}

264(6) A manner of fulfilling the purposes of public service television broadcasting in the United Kingdom is compatible with this subsection if it ensures-

(a) that the relevant television services (taken together) comprise a public service for the dissemination of information and for the provision of education and entertainment;

(b) that cultural activity in the United Kingdom, and its diversity, are reflected, supported and stimulated by the representation in those services (taken together) of drama, comedy and music, by the inclusion of feature films in those services and by the treatment of other visual and performing arts;

(c) that those services (taken together) provide, to the extent that is appropriate for facilitating civic understanding and fair and well-informed debate on news and current affairs, a comprehensive and authoritative coverage of news and current affairs in, and in the different parts of, the United Kingdom and from around the world;

(d) that those services (taken together) satisfy a wide range of different sporting and other leisure interests;

(e) that those services (taken together) include what appears to OFCOM to be a suitable quantity and range of programmes on educational matters, of programmes of an educational nature and of other programmes of educative value;

(f) that those services (taken together) include what appears to OFCOM to be a suitable quantity and range of programmes dealing with each of the following, science, religion and other beliefs, social issues, matters of international significance or interest and matters of specialist interest;

(g) that the programmes included in those services that deal with religion and other beliefs include-

(i) programmes providing news and other information about different religions and other beliefs;

(ii) programmes about the history of different religions and other beliefs; and

(iii) programmes showing acts of worship and other ceremonies and practices (including some showing acts of worship and other ceremonies in their entirety);

(h) that those services (taken together) include what appears to OFCOM to be a suitable quantity and range of high quality and original programmes for children and young people;

(i) that those services (taken together) include what appears to OFCOM to be a sufficient quantity of programmes that reflect the lives and concerns of different communities and cultural interests and traditions within the United Kingdom, and locally in different parts of the United Kingdom;

(j) that those services (taken together), so far as they include programmes made in the United Kingdom, include what appears to OFCOM to be an appropriate range and proportion of programmes made outside the M25 area.

Examining the stated purposes of PSB in the light of the analysis presented in Section 6 , the following features can be noted. A diverse range of programme types is specified, including comedy and drama, news and current affairs, religion, the arts,

87 'The M25 area' refers to the area within London's major ring road, i.e. the Greater London region. 
sports and other leisure interests. Moreover, 'matters of specialist interest' are explicitly mentioned. These can be interpreted as a response to the traditional market failure resulting in insufficient programme diversity: some of these genres would most likely be under-provided by advertising-funded broadcasters in the analogue era; although many others seem sufficiently popular to survive without intervention. ${ }^{88}$

The breadth of this remit - explicitly stating 'entertainment' as a purpose of PSB allows the BBC (the licence fee funded public broadcaster) to show considerable amounts of popular entertainment, especially during peak hours on its flagship channel, BBC1. It has also been used to justify the authorisation as PSB of new BBC channels covering general entertainment (BBC3) and rolling news (BBC News 24), to the dismay of commercial broadcasters.

Public service broadcasting also aims to mitigate traditional market failures regarding quality and innovation. Section 264(4) of the Act requires the maintenance of 'high general standards' in respect of programme content, production quality and editorial integrity. Specifying what 'quality' means precisely and monitoring this are difficult however; see relevant parts of Ofcom (2004a, b; 2005). Innovation is encouraged, most notably in relation to Channel 4 which is required under the Act to demonstrate 'innovation, experiment and creativity in the form and content of programmes'; as for quality, this is difficult to regulate.

The UK's historic PSB system, consisting of monopoly provision by a single public broadcaster (the BBC), provided poor incentives for innovation. The main spur to innovation has tended to come from competition, not always from desirable or legal sources. ${ }^{89}$ The recognition that competition could be beneficial led to the licensing of ITV (Channel 3) in 1955, and subsequently Channels 4 and 5. This has stimulated innovation somewhat, although both BBC and ITV have been criticised for lack of originality and use of derivative formats. ${ }^{90}$

Educational programmes and those 'of educative value' are included among the purposes of PSB under the Act. Coverage of news and current affairs must be comprehensive and authoritative, 'facilitating civic understanding and fair and wellinformed debate'. Programmes dealing with social issues are mentioned, as are those 'that reflect the lives and concerns of different communities' in the UK. These

88 Surveys conducted for the Ofcom review of public service television broadcasting indicate that several elements of PSB output are popular, with viewers placing a high value on their own consumption of news, serious factual programmes and drama, as well as entertainment; see Ofcom (2004a), Figure 33.

89 For example, in the early days of the Second World War some UK radio listeners found the Nazi propagandist Lord Haw Haw more entertaining than the BBC's austere diet of organ recitals and public announcements. This prompted the $\mathrm{BBC}$ to lighten its tone with a new emphasis on entertainment. In the $1960 \mathrm{~s}$, the BBC's failure to respond to changing music tastes led to the growth of pirate radio stations, culminating in harsh enforcement action - and also the launch of a new BBC station, Radio 1.

90 See, for example, the findings presented in Ofcom (2004a). 
specifications would seem to reflect various positive externalities associated with television: education, social concerns and the building of community understanding.

Certain exclusionary controls apply to television broadcasting. Advertising ceilings are placed on broadcasters to counter the bias toward excessive advertising in a freeto-air system. ${ }^{91}$ The BBC provides its channels advertising-free, motivated in part by the threat posed to editorial freedom from reliance on advertising revenue; though it should be noted that this may result in under-provision compared with the welfare (as opposed to viewer) optimum. Controls also exist on the broadcasting of potentially harmful material, in the form of broadcasting codes.

Turning now to provision, the UK's is a licensing system. Licences are awarded to a number of broadcasters, ${ }^{92}$ including both statutory (i.e. public) corporations (the BBC, Channel 4 and S4C) and commercial companies (the Channel 3 licensees, known collectively as 'ITV', Five and Teletext). Licences specify programme obligations (which vary between broadcasters) and are awarded for a number of years (the BBC's charter is typically renewed for ten years). Key facts about each public service broadcaster are summarised in Table 1; further details and historical background are contained in Appendix 2.

In return for programme obligations public service broadcasters are granted funding concessions, either a guaranteed revenue stream (the licence fee or government grant), or gifted spectrum from which advertising revenues are earned. Revenue from the licence fee, set at $£ 126.50$ per annum for a household in 2005-06, goes entirely to the BBC. All public service broadcasters hold gifted spectrum, for which the commercial licensees (the 'ITV' franchisees and Five) pay annual licence fees to the government, though lower amounts than would be paid in a purely commercial system. ${ }^{93}$ As public bodies Channel 4 and S4C pay no licence fees; S4C also receives a grant from the government and some programming from the BBC.

The public service broadcasters operate the only analogue channels, while on digital platforms they compete with other, fully commercial broadcasters. ${ }^{94}$ The BBC offers six digital-only channels in addition to its two analogue ones. All PSB channels are

91 Advertising ceilings are specified under the EU Television Without Frontiers directive.

92 The BBC has a Royal Charter rather than a licence. The remaining public service broadcasters are licensed under the Communications Act 2003.

93 Channel 3 ('ITV') licences were auctioned following the 1990 Broadcasting Act. Renewal fees for these and the Channel 5 licence (held by Five) are determined by Ofcom. In 2004 the licensees collectively paid $£ 230$ million. This is expected to fall to around $£ 90$ million in 2005 , reflecting the falling scarcity value of analogue spectrum resulting from the growth of digital households.

94 Digital satellite, operated by BSkyB, has near-universal coverage. There are two regional cable companies, NTL and Telewest, passing approximately 50\% of homes. Digital terrestrial television (DTT) has less than universal coverage but this is increasing, with a view towards digital switchover around 2012. Following the demise of ITV Digital in March 2002, Freeview, an umbrella platform for various free-to-air channels, was launched in October 2002. A limited payTV service, Top Up TV, was launched in March 2004. 
shown on the cable and satellite platforms under must-carry/must-provide regulations.

Table 1: UK public service broadcasters

\begin{tabular}{llll}
\hline Broadcaster & PSB channels & Structure & Funding \\
\hline $\begin{array}{l}\text { British Broadcasting } \\
\text { Corporation (BBC) }\end{array}$ & $\begin{array}{l}\text { BBC1, BBC2 } \\
+6 \text { digital-only }\end{array}$ & Statutory corporation & TV licence fee \\
\hline $\begin{array}{l}\text { Channel 3 licensees: } \\
\text { ITV plc, SMG, Ulster } \\
\text { TV, Channel TV and } \\
\text { GMTV }\end{array}$ & ITV1 & $\begin{array}{l}\text { Commercial companies; } \\
\text { ITV Network Centre } \\
\text { coordinates programming }\end{array}$ & Advertising \\
\hline Channel 4 Corporation & $\begin{array}{l}\text { Channel 4 } \\
\text { (not in Wales) }\end{array}$ & Statutory corporation & Advertising \\
\hline S4C & $\begin{array}{l}\text { S4C } \\
\text { (Wales only) }\end{array}$ & Statutory corporation & $\begin{array}{l}\text { Government grant, } \\
\text { advertising and } \\
\text { BBC programming }\end{array}$ \\
\hline Five & Five & $\begin{array}{l}\text { Commercial company owned } \\
\text { by RTL/Bertelsmann }\end{array}$ & Advertising \\
\hline Teletext & Text service & $\begin{array}{l}\text { Commercial company owned by } \\
\text { Harmsworth Media/DMGT and } \\
\text { Media Ventures International }\end{array}$ & Advertising \\
\hline & & & \\
\hline
\end{tabular}

\subsection{The impact of digital broadcasting}

With the growth of digital broadcasting the UK's system of PSB is facing a number of distinct but related threats to its long-term sustainability:

- public acceptance of the licence fee is in decline as more households adopt multi-channel TV;

- spectrum rents used to provide implicit subsidies to advertising-funded public service broadcasters are diminishing; and

- for commercial broadcasters, acceptance of programme obligations in return for gifted spectrum may prove unattractive close to digital switchover (even if some spectrum rents remain).

As discussed in Section 7, acceptance of a compulsory licence fee appears to fall as households adopt multi-channel (especially pay-) TV and their viewing of BBC channels declines. The BBC has recently been criticised by some for 'dumbing down' its output and engaging in ratings wars with ITV, in an attempt to maintain its popularity. Now faced with renewal of its charter in 2007, the BBC has changed tack with a campaign to define its role as the promoter of 'public value'. ${ }^{95}$ If the current level of licence fee funding cannot be defended and its public service role is to be maintained, the BBC may eventually need to raise revenue by alternative means (e.g. subscription) or be given funds from general taxation.

95 See BBC (2004). 
The licence obligations of the other public service broadcasters are funded by means of analogue spectrum concessions. ITV plc, the largest of the commercial public service broadcasters, has estimated its additional programming costs at around $£ 250 \mathrm{~m}$ per annum. ${ }^{96}$ As digitisation relaxes spectrum constraints and competitive entry takes place, the rents used to fund PSB obligations are being eroded. ${ }^{97}$ Ultimately, as these rents disappear, programme obligations must either be removed (and hence public service broadcasting largely abandoned, except by the $\mathrm{BBC}^{98}$ ), or subsidised out of public funds.

A further issue arises for the commercial public service broadcasters (the Channel 3 licensees and Five). As shareholder-controlled firms looking to maximise returns, their willingness to participate in PSB cannot be taken for granted (as it can for the BBC, Channel 4 and S4C). These companies have the option of abandoning (or not seeking to renew) their PSB licences, and instead undertaking purely commercial broadcasting on digital terrestrial and other platforms (although not on analogue terrestrial, for which spectrum is available only through the PSB licences). The relative return to the two modes of broadcasting is crucial to this decision. With costly PSB obligations, they will participate only if the benefits of PSB, relative to the commercial alternative, exceed this cost.

As noted above, digitisation undermines the value of spectrum concessions granted to public service broadcasters. Another possible benefit of participation in PSB is 'due prominence' on electronic programme guides (EPGs) given to PSB channels. But although EPG positioning is important to broadcasters since this allows their channels to be found more easily, ${ }^{99}$ prominence might be obtained in other ways. ${ }^{100}$ In any case, this value is unlikely to be sufficient to sustain a lot of costly PSB obligations. A further incentive for continued participation over the next few years is that, until digital switchover, PSB licences retain a value from linkages between analogue and digital viewing. As well as carrying their existing analogue audiences over to the digital platform, giving these channels an inherited advantage in the digital world,

96 From The Times, 'ITV unveils strategy for digital fightback', 24 June 2004.

97 In practical terms, the audiences and advertising revenues of advertising-funded public service channels are coming under pressure. Concern has already been raised over the future viability of Channel 4 (see 'Preserving C4's provision', Financial Times, 19 April 2004, written by Mark Thompson, then Chief Executive of Channel 4). Although S4C also sells advertising, the major part of its funding comes from a government grant and it is therefore largely protected from this threat.

98 The concern that public service output on advertising-funded channels will eventually disappear underlies Ofcom's proposal to create a 'Public Service Publisher' (PSP) to compete with the BBC. A public funding source would be needed for this body, however, with the practical options being limited to top-slicing licence fee revenue (assuming that the licence fee itself can be defended) or a grant out of taxation.

99 EPG positioning has been the subject of several disputes between broadcasters, including the positioning of BBC channels on the satellite EPG and of Top-Up TV's channels on the digital terrestrial EPG.

100 For example, EPG rankings by viewing shares would place the existing analogue channels at or close to the top of the list due to their inherited base of viewers. 
broadcasters can (and do) use airtime on their analogue channels to cross-promote their digital services, and thus increase viewing shares for all their digital channels. Until digital switchover becomes imminent, commercial broadcasters are unlikely to want to abandon their PSB licences.

Although it is unclear precisely how these calculations stack up, serious threats to the long-term sustainability of ITV1, Channel 4 and Five as PSB channels must be recognised. Under the worst case scenario the $\mathrm{BBC}$ will be left as the only significant provider of PSB. Moreover, with support for the television licence fee in decline, even the BBC's position cannot be seen as unassailable.

Although it may be possible to prop up the PSB system, perhaps by increasing direct public funding and spreading this between a wider range of providers, it must be questioned whether this is actually worthwhile. Market provision in the digital world is far less prone to traditional market failures, and will supply broadly the programmes that viewers wish to watch. Although remaining externality and 'citizenship' concerns provide a rationale for on-going, but much more limited, public intervention, the weakening of broadcasters' ability to ensure that public service material is actually watched undermines the effectiveness of such intervention. It would not be unreasonable to conclude that, given the declining benefits and major costs of intervening in this market, including the distortion to competition due to the presence of a state-funded broadcaster, the time has now come when large-scale intervention is no longer appropriate.

\section{Conclusion}

To conclude, we put forward key messages from our analysis for students, researchers and policymakers.

\section{Messages for students}

For the student, the following conclusions may be drawn from this chapter.

- Advertising-funded broadcasting is prone to a number of market failures. In particular:

- an insufficiently diverse range of programme genres is produced;

- programme quality is too low;

- innovation incentives are weak; and

- the airtime devoted to advertising tends to be excessive, especially if its nuisance cost to viewers is high. This is a form of allocative inefficiency.

- When broadcasters can charge viewers (i.e. in pay-TV) these biases are largely mitigated. Compared with advertising-funded broadcasting:

- a diverse range of programme genres is produced, satisfying the breadth of viewers' tastes;

- quality is higher, and broadly appropriate to viewers' willingness-to-pay; 
- incentives to invest in innovative programming are higher;

- fewer adverts are shown, benefiting viewers but harming advertisers; and

- price discrimination through channel bundling can mitigate inefficient exclusion of viewers.

- Spectrum scarcity in analogue broadcasting creates a barrier to entry, limiting competition and generating scarcity rents. Digital technologies relax spectrum constraints and facilitate competitive entry, eliminating rents.

- A number of externalities are cited for television broadcasting, both positive and negative.

\section{Messages for researchers}

There is a long literature on the economics of broadcasting, stretching back almost 60 years. We have drawn on many of these papers in this chapter. Even so, a number of important questions call out for further research, especially empirical investigation.

- To what extent is excess entry a significant issue in digital broadcasting?

- How can the 'quality' of television programmes (in the sense defined in Section 3 of this chapter) be measured? What underlying factors does it depend on?

- As the ownership and use of personal video recorders becomes widespread, to what extent do people use its enhanced capabilities to avoid advertising in television? What is the impact on advertising revenue? Can we infer from such behaviour the disutility of advertising for viewers?

- Can robust evidence be gathered about the relationship between television viewing and individual behaviour? What are the behavioural effects of television viewing in general? What are the behavioural effects of viewing specific types of programming?

- Can the various externalities cited for broadcasting be quantified?

\section{Messages for policymakers}

The future of public service broadcasting has been the focus of recent policy debate in the UK. The UK is currently in a period of transition between analogue and digital broadcasting: the number of homes that have adopted digital television is steadily increasing, ${ }^{101}$ and digital switchover is due to be completed by 2012 . Thus, the impact of digitisation on public service broadcasting needs to be recognised and addressed in the near future. As a contribution to this debate, both in the UK and elsewhere, we put forward the following recommendations for policymakers:

- Public service broadcasting systems in countries such as the UK were coherent responses to the market failures inherent in advertising-funded broadcasting,

101 As of end March 2005, 61.9\% of UK households were capable of receiving digital television (Ofcom, The Communications Market 2005, Section 4.2.1). 
and thus were relevant in the analogue era. Digital broadcasting is less prone to traditional market failures and will supply the programmes that viewers broadly wish to watch. With this development, the 'market failure' rationale for PSB largely falls away.

- The remaining rationale for public intervention is linked to externality and 'citizenship' concerns. There is a case for continued intervention, but of more limited form and at a scale appropriate to the magnitude of these externalities.

- Although wider benefits of public service content may merit intervention, the ability to ensure actual viewing of programmes that do not appeal directly to the viewer's own preferences is increasingly constrained in the digital world. If public service messages are to gain viewer attention, methods similar to 'product placement' may be required. If significant audiences cannot be captured, policymakers should reconsider whether continued intervention is appropriate.

- Relaxation of spectrum constraints will eliminate the rents currently used as an implicit source of funding for part of the UK's public service output. One possibility is to replace this amount with public funds. But raising the level of public funding at a time when the rationale for, and effectiveness of, PSB is declining would be highly questionable.

\section{Appendix 1: A duopoly model of programme quality}

This appendix presents the formal model discussed in Section 3. There are two broadcasters, $A$ and $B$, each supplying a single channel. ${ }^{102}$ Suppose that over the relevant period each viewer watches a single channel. There is an exogenous level of horizontal product differentiation between the two channels: if broadcaster $i$ supplies viewers with utility $u_{i}$ it will obtain a market share of viewers given by the Hotelling formula

$$
s_{i}=\frac{1}{2}+\frac{u_{i}-u_{j}}{2 t}
$$

where $t>0$ measures the exogenous degree of channel differentiation and $u_{j}$ is utility provided by the rival broadcaster. Utility $u_{i}$ is made up of three ingredients:

$$
u_{i}=v_{i}-\delta n_{i}-p_{i}
$$

102 The following model is similar to Anderson and Coate (2005) except that here the quality of programmes is chosen by the broadcasters. For related theoretical models of competition between broadcasters, see Crampes et al. (2005) and Peitz and Valletti (2004). The former paper, which has exogenous programme quality, examines a free-entry model of broadcasting (or media more generally) and also allows the advertising revenue function to be non-linear (unlike the model described in this appendix). The second paper models (duopoly) broadcasters as choosing the degree of horizontal differentiation, i.e. the degree of programme diversity, rather than (vertical) programme quality. 
where $v_{i}$ is the endogenous quality of the broadcaster's output, $n_{i}$ is the number of adverts shown on the channel, and $p_{i}$ is the subscription charge (if any). The parameter $\delta$ represents the perceived nuisance of adverts to viewers. Suppose that a broadcaster's advertising revenue is proportional to its audience. More precisely, suppose that if a broadcaster chooses a quantity of advertising $n$ it receives advertising revenue $R(n)$ per viewer. Assume that there are decreasing returns to the number of adverts shown, in the sense that $R(\cdot)$ is a concave function. A broadcaster can choose its quality $v_{i}$ by incurring the quadratic fixed cost $\gamma v_{i}^{2} / 2$. There are no other costs involved in delivering programmes to viewers. In sum, the profit of broadcaster $i$ is

$$
\pi_{i}=\left(\frac{1}{2}+\frac{v_{i}-\delta n_{i}-p_{i}-\left(v_{j}-\delta n_{j}-p_{j}\right)}{2 t}\right)\left(p_{i}+R\left(n_{i}\right)\right)-\frac{1}{2} \gamma w_{i}^{2}
$$

We next analyse the outcomes of this model, first in the case where broadcasters can charge directly for viewing, and then when broadcasters must rely on advertising revenue alone to fund their operations.

\section{Pay TV regime}

One can show that broadcaster $i$ 's profit in (1) is concave in $\left(p_{i}, v_{i}\right)$ if and only if

$$
4 t \gamma>1 \text {, }
$$

and this is assumed henceforth. (If this condition does not hold, then there is no market sharing equilibrium, and a channel wishes to corner the market for viewers by setting a high quality level.)

Since $p_{i}=v_{i}-u_{i}-\delta n_{i}$, broadcaster $i$ 's profit in expression (1) can be written as

$$
\pi_{i}=\left(\frac{1}{2}+\frac{u_{i}-u_{j}}{2 t}\right)\left(v_{i}-u_{i}+R\left(n_{i}\right)-\delta n_{i}\right)-\frac{1}{2} \gamma v_{i}^{2} .
$$

Therefore, it is a dominant strategy (i.e., regardless of the broadcaster's chosen level of utility $u_{i}$ ) for each broadcaster to choose the advertising intensity $n_{1}$, where

$$
n_{1} \text { maximises } R(n)-\delta n \text {. }
$$

Given market share $s_{i}$, which is determined by the two broadcasters' choices of utilities $u_{i}$ and $u_{j}$, firm $i$ 's most profitable choice of quality is given by $v_{i}=s_{i} / \gamma$. Thus, when subscription charges are used, private and social incentives to supply quality coincide, and broadcasters supply the socially optimal level of programme quality given the size of their audience. (This result is an artefact of the assumption that all viewers have the same preferences about programme quality.)

One can calculate that the symmetric equilibrium subscription price and quality are respectively given by 


$$
p_{1}=t-R\left(n_{1}\right) ; v_{1}=\frac{1}{2 \gamma}
$$

Note from (4) that if $R\left(n_{1}\right)>t$ then firms would like to charge a negative price for viewing: the revenue from advertising is so great that firms wish to pay viewers to watch. Since this outcome is not likely to be feasible in practice, we impose a nonnegativity constraint on subscription prices. With this assumption, if parameters are such that $R\left(n_{1}\right)>t$ then the regime of 'pay-TV' collapses to the free-to-air advertisingfunding regime, since firms do not charge viewers (even though they could). Therefore, differences between the two regimes only exist when

$$
R\left(n_{1}\right)<t
$$

and this is assumed henceforth.

Broadcasters break even if and only if the concavity condition (2) is satisfied, in which case the industry profit is $t-1 /(4 \gamma)$. Notice that this equilibrium profit is increasing in $\gamma$, the cost of making better programmes. (Of course, keeping a rival broadcaster's actions fixed, one broadcaster's profits will decrease if its cost $\gamma$ rises. However, when each firm's cost rises, there is a strategic effect that softens competition, and the net effect in this model is for equilibrium profits to rise.)

One policy intervention that would increase viewer surplus (but not overall welfare) is to require channels to raise the quality of their programmes above the equilibrium level of $v=1 /(2 \gamma)$. As long as this does not cause the channels to go bankrupt, it has no effect on the prices offered to viewers. Of course, however, programme quality is something that is intrinsically hard to regulate.

Finally, consider the effect of advertising becoming impossible (say, due to the widespread adoption of PVRs). In this model, the only effect is to increase the price to viewers, and programme quality is not affected. Viewers are strictly worse off: the increase in price outweighs a viewer's benefit of not having to watch adverts. The equilibrium level of advertising in expression (3) describes a viewer's ideal amount of advertising, given that the revenue from advertising is passed on to the viewer in the form of a reduced subscription charge. A similar point is that, in the pay-TV regime, there is no argument (even from the perspective of viewers alone) for regulation that places a ceiling on the amount of advertising that broadcasters show.

\section{Advertising-funded TV}

Turning next to the advertising-only framework, a broadcaster's profit is

$$
\pi_{i}=\left(\frac{1}{2}+\frac{v_{i}-\delta n_{i}-\left[v_{j}-\delta n_{j}\right]}{2 t}\right) R\left(n_{i}\right)-\frac{1}{2} \gamma v_{i}^{2} .
$$


(This is just expression (1) with the subscription prices set equal to zero.) The firstorder conditions for symmetric equilibrium in advertising intensity and programme quality are

$$
\frac{R^{\prime}\left(n_{2}\right)}{R\left(n_{2}\right)}=\frac{\delta}{t}
$$

and

$$
v_{2}=\frac{R\left(n_{2}\right)}{2 t \gamma} .
$$

From (3), (5) and (7) we have

$$
\frac{R^{\prime}\left(n_{1}\right)}{R\left(n_{1}\right)}=\frac{\delta}{R\left(n_{1}\right)}>\frac{\delta}{t}=\frac{R^{\prime}\left(n_{2}\right)}{R\left(n_{2}\right)} .
$$

By concavity, the function $R^{\prime} / R$ is decreasing in $n$, and so we deduce that there is less advertising in the pay-TV regime than in the advertising-funded regime.

Since $n_{2}>n_{1}$ it follows by concavity that $R^{\prime}\left(n_{2}\right)<R^{\prime}\left(n_{1}\right)=\delta$, and so expression (6) demonstrates that $R\left(n_{2}\right)<t$. This inequality implies that quality $v_{2}$ in (7) is lower than in the pay-TV regime, when quality was given by $v_{1}=1 /(2 \gamma)$. Of course, in the case of advertising-funded television, the widespread adoption of PVRs would most likely prove fatal.

We must check that broadcasters break even in this model with advertising funding. Industry profits are

$$
R\left(n_{2}\right)-\gamma v_{2}^{2}=R\left(n_{2}\right)\left(1-\frac{R\left(n_{2}\right)}{4 \gamma t^{2}}\right),
$$

where the equality follows from (7). Notice that these profits are 'inverse-U' shaped in advertising revenue: too little advertising revenue obviously leads to low profits, but too much revenue causes firms to compete very hard for viewers by offering high quality programmes, and this drives down profits. As in the pay-TV regime, the broadcasters' profits are increasing with $\gamma$. The above expression shows that profits are positive provided that $R\left(n_{2}\right)<4 \gamma t^{2}$. However, we have just shown that $R\left(n_{2}\right)<t$, and so a sufficient condition for this is that $4 \gamma t>1$, which is exactly the condition (2) that ensures that the broadcasters break even in the pay-TV regime. Therefore, whenever broadcasters break even in the pay-TV regime they will also break even when they must rely on advertising alone. (Note that we are not suggesting that profits are higher with free-to-air broadcasting; in many cases they will not be.) 


\section{Comparison of viewer surplus}

Finally, we can compare viewer surplus in the two funding regimes. First, consider the case of exogenously fixed programme quality $v$ (or, equivalently, the case of very large $\gamma$ ). In this case, viewers in the pay-TV regime have utility

$$
u_{1}=v+R\left(n_{1}\right)-t-\delta n_{1}
$$

whereas in the free-to-air regime, viewer utility is

$$
u_{2}=v-\delta n_{2} .
$$

When $t<R\left(n_{1}\right)$ the two regimes coincide if negative prices are not feasible. When $t=$ $R\left(n_{1}\right)$ one can check that $n_{1}=n_{2}$ and so expressions (8) and (9) are equal. Next, consider the effect on the two utilities of raising $t$ above $R\left(n_{1}\right)$. Clearly, from expression (8) we have $\mathrm{d} u_{1} / \mathrm{d} t=-1$. However, by differentiating expression (6) it follows from (9) that $\mathrm{d} u_{2} / \mathrm{d} t \geq-1$. We deduce that for $t>R\left(n_{1}\right)$, i.e., in all situations where the two funding regimes are different, viewers are worse off in the pay-TV regime when programme quality is fixed. The benefit that viewers obtain from seeing fewer adverts is outweighed by the extra price they must pay to subscribe.

The effect of making programme quality endogenous, however, can reverse viewer preferences over the two regimes. Take the linear example where $R(n)=\alpha n$ and where $\alpha<\delta$. In this case, a pay-TV channel (which chooses $n_{1}$ to maximise $R(n)-\delta n$ ) will not offer any adverts, and so from (4)

$$
u_{1}=\frac{1}{2 \gamma}-t
$$

A free-to-air channel will, from (6) and (7), choose

$$
n_{2}=\frac{t}{\delta} ; v_{2}=\frac{\alpha}{2 \delta \gamma}
$$

which yields a lower viewer utility: $u_{2}<u_{1}$. Thus, in this case, the higher quality programmes in the pay-TV regime more than compensate viewers for the higher price they pay to watch programmes.

To summarise the main results derived in this duopoly model:

- compared to the pay-TV regime, advertising-funded broadcasting involves lower quality programmes and more adverts; and

- viewers are better off in a free-to-air regime if there is little scope for affecting programme quality, while they are better off in a pay-TV regime otherwise.

\section{Appendix 2: Public service broadcasters in the UK}

The UK has five public service television broadcasters: the British Broadcasting Corporation (BBC), the ITV network (properly known as Channel 3), Channel 4 (except in Wales), S4C (in Wales only) and Five. A TV-based information service, 
Teletext, is also licensed as a public service broadcaster. These broadcasters are subject to explicit programming and production obligations in relation to their PSB channels, in return for either a guaranteed funding stream or gifted spectrum from which advertising and sponsorship revenues may be earned. Along with all other broadcasters they must also meet basic standards of taste and decency, accuracy and impartiality required of all broadcasters.

There are several important differences in the nature and funding of the various public service broadcasters. These are detailed as follows.

\section{The $B B C$}

The BBC is a statutory corporation. It was founded as the British Broadcasting Company in 1922 by a group of wireless manufacturers to transmit radio (rather than television) broadcasts. In 1927 it received its first Royal Charter and became the British Broadcasting Corporation. It began television broadcasts in 1936. Its current Charter is up for renewal in 2006. The BBC is largely self-governing, with various regulatory functions being in the hands of its own Governors.

The BBC's PSB channels and services are funded from a licence fee of $£ 126.50$ per annum (in 2005-06) paid by every TV household (with concessions for those aged over 75 and the blind). This raises annual revenues for the BBC of $£ 2.94 \mathrm{bn}$ a year (in 2004-05). In addition, the BBC's income from its commercial businesses totalled $£ 151 \mathrm{~m}$ in 2004-05. The BBC operates two analogue channels, BBC1 and BBC2. It has a further six digital PSB channels, shown free-to-air: BBC3, BBC4, BBC News 24, BBC Parliament and the children's channels CBeebies and CBBC. It also has a text information service, Ceefax, which started transmission in 1974.

\section{Channel 3 ('ITV')}

Channel 3, generally known as ITV, was established in 1955. It is a network of 15 distinct regional licences, each with its own set of public service obligations designed to reflect the particular character of the region. ITV plc, formed by the merger of Carlton and Granada in February 2004, owns the eleven Channel 3 licences in England and Wales. Scottish Media Group (SMG plc) holds the two licences for Scotland, while Ulster Television plc and Channel Television Ltd hold one licence each, for Northern Ireland and the Channel Islands respectively. There is also a national licence for breakfast-time TV, held by GMTV Ltd.

The Channel 3 licensees are shareholder-controlled companies. They benefit from gifted spectrum and pay licence fees to the government. The Channel 3 network's PSB channel, ITV1, is advertising funded. It is licensed under Section 216 of the Communications Act 2003, which sets out its PSB obligations and provides for both analogue and digital transmission, and is regulated by Ofcom (formerly by the Independent Television Commission, ITC). Over 90\% of the programmes shown on ITV1 are common across the regional licence areas: these are coordinated through the 
ITV Network Centre, which commissions and schedules programmes for broadcast over the network as a whole. There is a small element of regional programming in each area, as required under the licences.

In addition to ITV1, there are currently three further ITV channels: ITV2 and IV3, which are wholly owned by ITV plc, and ITV News. These channels are available on digital platforms only, and are outside the public service broadcasting system.

\section{Channel 4}

Channel 4, along with S4C in Wales (see below), was created by Act of Parliament in 1982. C4C (the Channel 4 Corporation) is a statutory corporation, headed by a board appointed by Ofcom in agreement with the Secretary of State for Culture, Media and Sport. It receives no public funds, being funded from its own advertising revenue and other commercial activities.

Channel 4 is required under the Communications Act 2003 to provide of a broad range of high quality and diverse programming which: demonstrates innovation, experimentation and creativity; appeals to the tastes and interests of a culturally diverse society; includes programmes of an educational nature; and exhibits a distinctive character. It is a commissioning broadcaster, not a producer, purchasing its programming from over 300 independent production companies across the UK.

In addition to its PSB channel, the Channel Four Group also operates two pay-TV channels: E4, a general entertainment channel, and FilmFour, a specialist film channel. The FilmFour division produces and co-produces feature films for the UK and global markets.

\section{S4C}

S4C (Sianel Pedwar Cymru, or 'Channel Four Wales'), is a statutory corporation established in 1982 (alongside Channel 4) to broadcast in Wales. It is regulated by the Welsh Authority, whose chair and members are appointed by the Secretary of State for Culture, Media and Sport in consultation with the National Assembly for Wales. It has the distinctive role as public service broadcaster to the bilingual community in Wales, with Welsh language broadcasts an important part of its remit. It is supported by a government grant ( $£ 85.7 \mathrm{~m}$ in 2004$)$ in addition to its own advertising revenues, and receives some programming from the BBC provided using licence fee funding.

Like Channel 4, S4C is a commissioning broadcaster, not a producer. During peak hours (18:00-22:00) the majority of its output must be in the Welsh language; in total it carries an average of 32 hours of Welsh language programming each week. Of this, ten hours a week is provided by the BBC while the rest is commissioned from independent producers including the local ITV franchise, HTV (part of ITV plc). The rest of S4C's output is English language programming from Channel 4, over 70\% of whose output is shown on $\mathrm{S} 4 \mathrm{C}$, usually rescheduled. 


\section{Five}

Channel 5 (now rebranded as 'Five') was launched in March 1997. It has restricted coverage (its analogue signal reaches around $82 \%$ of UK homes, though this is being expanded by digital coverage) and inferior picture quality in some areas due to low transmission power. It is a shareholder-controlled company, majority owned by RTL/ Bertelsmann, and is funded from sales of advertising airtime. It has very little inhouse production, relying mainly on original commissions and acquired programming.

\section{Teletext}

Teletext provides the analogue text services on ITV1, Channel 4 and Five. Teletext is also available on digital TV, the Internet and mobile phones. The first full text services, BBC Ceefax and Oracle (operated by ITV), began transmission in 1974. Teletext, an independent franchise, took over from Oracle at the start of 1993. Teletext Ltd. is a commercial organisation owned by Harmsworth Media (a subsidiary of the Daily Mail and General Trust) and Media Ventures International.

\section{References}

Adams, William, and Janet Yellen. 1976. 'Commodity bundling and the burden of monopoly'. Quarterly Journal of Economics 90: 475-498.

Anderson, Simon, and Stephen Coate. 2005. 'Market provision of broadcasting: a welfare analysis'. Review of Economic Studies, forthcoming.

Armstrong, Mark. 1999. 'Price discrimination by a many-product firm'. Review of Economic Studies 66: 151-168.

Bakos, Yannis, and Erik Brynjolfsson. 1999. 'Bundling information goods: pricing, profits and efficiency’. Management Science 45: 1613-1630.

Beebe, Jack H. 1977. 'Institutional structure and program choices in television markets'. Quarterly Journal of Economics 91: 15-37.

Besley, Timothy, and Andrea Prat. 2004. 'Handcuffs for the grabbing hand? Media capture and government accountability'. Mimeo.

BBC. 2004. Building Public Value: Renewing the BBC for a Digital World.

Brookes, Martin. 2004. Watching Alone: Social Capital and Public Service Broadcasting. BBC and The Work Foundation.

Camerer, Colin, Samuel Issacharoff, George Loewenstein, Ted O'Donoghue and Matthew Rabin. 2003. 'Regulation for conservatives: behavioural economics and the case for "asymmetric paternalism"'. University of Pennsylvania Law Review 151: 1210-1254.

Coase, Ronald H. 1946. 'The marginal cost controversy'. Economica 13: 169-182.

Coase, Ronald H. 1948. 'Wire broadcasting in Great Britain'. Economica 15: 194220. 
Coase, Ronald H. 1950. British Broadcasting: A Study in Monopoly. Longmans, Green and Co., London.

Coase, Ronald H. 1966. 'The economics of broadcasting and government policy'. American Economic Review 56: 440-447.

Crampes, Claudes, Carole Haritchabalet and Bruno Jullien. 2005. 'Competing with advertising resources'. Mimeo.

Davies, Gavyn. 1999. The Future Funding of the BBC. Report of the Independent Review Panel to Department of Culture, Media and Sport.

DCMS. 2005. Review of the BBC's Royal Charter: A strong BBC, Independent of Government. Department for Culture, Media and Sport Green Paper (March).

Elstein, David. 2004. Beyond the Charter: The BBC after 2006. Broadcasting Policy Group.

Gentzkow, Matthew. 2004. 'Television and voter turnout'. Mimeo, Harvard University.

Hansen, Claus Thustrup, and Søren Kyhl. 2001. 'Pay-per-view broadcasting of outstanding events: consequences of a ban'. International Journal of Industrial Organization 19: 589-609.

Matutes, Carmen, and Pierre Regibeau. 1992. 'Compatibility and bundling of complementary goods in a duopoly'. Journal of Industrial Economics 40: 37-54.

McAfee, Preston, John McMillan and Michael Whinston. 1989. 'Multiproduct monopoly, commodity bundling, and correlation of values'. Quarterly Journal of Economics 104: 371-384.

Nalebuff, Barry. 2003. Bundling, Tying and Portfolio Effects. Part 1: Conceptual Issues. DTI Economics Paper 1.

Ofcom. 2004a. Ofcom Review of Public Service Television Broadcasting. Phase 1 - Is Television Special? (April).

Ofcom. 2004b. Ofcom Review of Public Service Television Broadcasting. Phase $2-$ Meeting the Digital Challenge (September).

Ofcom. 2005. Ofcom Review of Public Service Television Broadcasting. Phase 3 Competition for Quality (February).

Oliver, Mark. 2005. 'The UK's public service broadcasting ecology'. In Can the Market Deliver? Funding Public Service Television in the Digital Age. John Libby Publishing.

Peacock, Alan. 2004. 'Public service broadcasting without the BBC?' In Public Service Broadcasting without the BBC? Institute of Economic Affairs, London.

Peitz, Martin and Tommaso Valletti. 2004. 'Content and advertising in the media: pay-TV versus free-to-air'. Mimeo.

Prat, Andrea and David Strömberg. 2004. 'State television and voter information'. Mimeo. 
Putnam, Robert D. 2000. Bowling Alone: The Collapse and Revival of American Community. Simon and Schuster.

Spence, Michael. 1975. 'Monopoly, quality and regulation'. Bell Journal of Economics 6: 417-429.

Spence, Michael, and Bruce Owen. 1977. 'Television programming, monopolistic competition, and welfare'. Quarterly Journal of Economics 91: 103-126.

Spitzer, Manfred. 2005. Vorsicht Bildschirm! Klett Ernst Verlag GmbH.

Steiner, Peter O. 1952. 'Program patterns and preferences, and the workability of competition in broadcasting'. Quarterly Journal of Economics 66: 194-223.

Strömberg, David. 2004a. 'Mass media competition, political competition, and public policy'. Review of Economic Studies, forthcoming.

Strömberg, David. 2004b. 'Radio's impact on public spending'. Quarterly Journal of Economics, forthcoming.

Terrington, Simon and Caroline Dollar. 2005. 'Measuring the value created by the BBC'. In Can the Market Deliver? Funding Public Service Television in the Digital Age. John Libby Publishing.

Whinston, Michael. 1990. 'Tying, foreclosure and exclusion'. American Economic Review 80: 837-859.

Wilbur, Kenneth. 2004. 'Modeling the effects of advertisement-avoidance technology on advertisement-supported media: the case of digital video recorders'. Mimeo, University of Virginia. 